SC-R $-65-997$

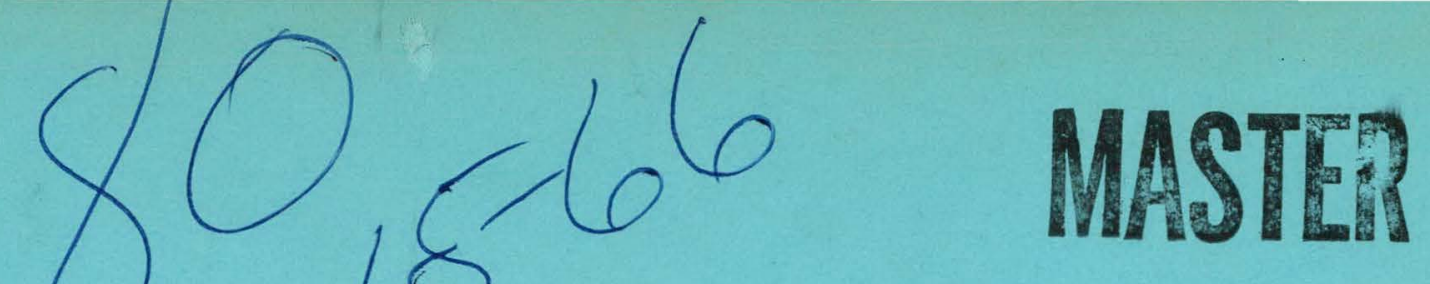

DESIGN CONSIDERATIONS FOR ION PLATING

D. M. Mattox 


\section{DISCLAIMER}

This report was prepared as an account of work sponsored by an agency of the United States Government. Neither the United States Government nor any agency Thereof, nor any of their employees, makes any warranty, express or implied, or assumes any legal liability or responsibility for the accuracy, completeness, or usefulness of any information, apparatus, product, or process disclosed, or represents that its use would not infringe privately owned rights. Reference herein to any specific commercial product, process, or service by trade name, trademark, manufacturer, or otherwise does not necessarily constitute or imply its endorsement, recommendation, or favoring by the United States Government or any agency thereof. The views and opinions of authors expressed herein do not necessarily state or reflect those of the United States Government or any agency thereof. 


\section{DISCLAIMER}

Portions of this document may be illegible in electronic image products. Images are produced from the best available original document. 
Published by

Sandia Corporation,

a prime contractor to the

United States Atomic Energy Commission

\section{LEGAL NOTICE}

This report was prepared as an account of Covernment sponsored work,
Neither the United States, nor the Commission, nor any person acting on behalf of the Commission:

A. Makes any warranty or representation, expressed or implied, with respect to the accuracy, completeness, or usefulness of the information contained in this report or that the use of any information, apparatus, method, or process
disclosed in this report may not infringe privately owned rights; or disclosed in this report may not intringe privately owhed nghts; of

B. Assumes any liabilities with respect to the use of, or for damages resulting from the
in this report,

As used in the above, "person acting on behalf of the Commission" includes any employee or contractor of the Commission, or employee of such contractor,
to the extent that such exiaployee or contractor of the Cammission or employee of such contractor prepares, disseminates, or provides aecess to, any information pursuant to his employment or contract with the Commission, or his employment with such contractor. 


\section{DESIGN CONSIDERATIONS FOR ION PLATING *}

D. M. Mattox

January 1966

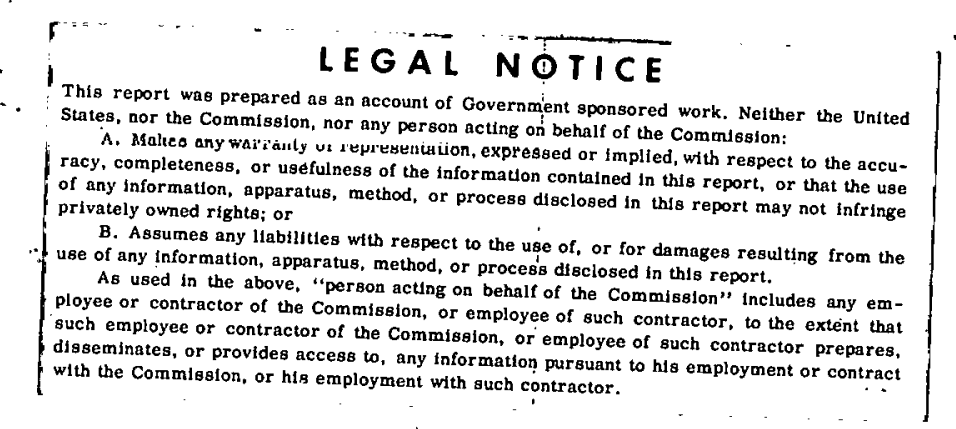

Printed in USA. Price \$3.00. Available from the Clearinghouse for Federal Scientific and Technical Information, National Bureau of Standards,

U. S. Department of Commerce, Springfield, Virginia

\footnotetext{
* This work was supported by the U. S. Atomic Energy Commission. Reproduction in whole or in part is permitted for any purpose of the United States Government.
} 


\begin{abstract}
A discussion is given of the important design considerations useful in setting up and using apparatus for ion plating. Apparatus and techniques which have proven to be reliable are presented and discussed. Reviews of sputtering and gaseous electronics as applied to ion plating are given in the Appendices.
\end{abstract}


Introduction

Equipment

Evaporation: Sources and Techniques 12

Positioning of Parts 13

Substrate Pretreatment $\quad 15$

Process Controls 18

Conclusion

LIST OF REFERENCES ? ? 19

APPENDIX A--GASEOUS ELECTRONICS ${ }^{\mathrm{A} 1}$.

APPENDIX B--SPUTTERING 41

LIST OF ILLUSTRATIONS

\section{Figure}

1. A simple ion plating apparatus using a conventional glass belljar vacuum system. The high voltage feedthrough is shown in Figure 3

2. A cold finger cathode made by connecting a section of glass pipe to the top of a conventional glass belljar. The sides of the cold finger are shielded from ion bombardment by the floating shield

3. A simple shielded high voltage feedthrough on a copper tube which may be bent to any configuration

4. A high voltage connection for use in a Vacuum System with a support plate

5. A setup for holding a large piece to be ion plated using shielded rods for support

6. A setup for holding another large piece showing a different support and evaporation configuration

7. Distribution of copper ion plating on an aluminum tube. Thickness in mils

8. A cathode arrangement used to plate insulators. The grid is present to prevent charge buildup on the insulator surface 


\title{
DESIGN CONSIDERATIONS FOR ION PLATING
}

\author{
Introduction
}

In the ion plating deposition technique, ${ }^{1,2}$ consideration must be given to a number of factors which are not present in vacuum evaporation or sputtering. The difficulties encountered in using the ion plating process are usually associated with equipment, substrate positioning or surface pretreatment. In an attempt to help people avoid some of these difficulties, this paper has been written based on our experiences in this laboratory and the experiences of other persons who have set up the process for their own use or under contract.

\section{Equipment}

Standard commercial vacuum units are most often used. Any system capable of providing a vacuum of $1 \times 10^{-6}$ torr or better is sufficient for most applications.

Since a continuously flowing gas supply is normally used, backstreaming of pump oils during cleaning and deposition is minimized. The gas load is high, therefore it is desirable to use a larger forepump than is normally required. Diffusion pumped systems may or may not be equipped with cold traps. If the procedure requires that there be only a small amount of ion bombardment cleaning before deposition, the system should have a cold trap to give a lower ultimate pressure and less contamination. Under no circumstances should the roughing pump be used to directly control the gas flow through the system since backstreaming of the oils from a roughing pump is much higher than from a diffusion pump.

To control the gas pressure in the chamber, it is helpful to be able to throttle the gate valve between the chamber and the vacuum pump. This may easily be done if the gate valve is manually operated; however, if the valve is operated hydraulically or pneumatically, a butterfly valve or shutter in the throat may be used to give manual control of the pumping speed. A disadvantage of throttling is that the decreased pumping speed increases the problems associated with contamination by outgassing during deposition.

Plastics and rubber should not be used in the system as they tend to decompose under glow. discharge conditions and contaminate the system.

A simple system using a glass belljar is shown in Figure 1. A glass belljar has a tendency to build up a surface charge which may arc to ground until the surface becomes covered with metal. Therefore, it is desirable to coat the internal surface of the belljar with a vacuum-deposited metal coating before beginning ion plating. A window may be left for visual observation of the process. Usually aluminum is used as the coating material and is easily removed with sodium hydroxide. If the metal coating in the belljar does not make contact with ground, a charge may build up and arc across the sealing gasket to ground. Metal belljars should be grounded to prevent charge buildup. 


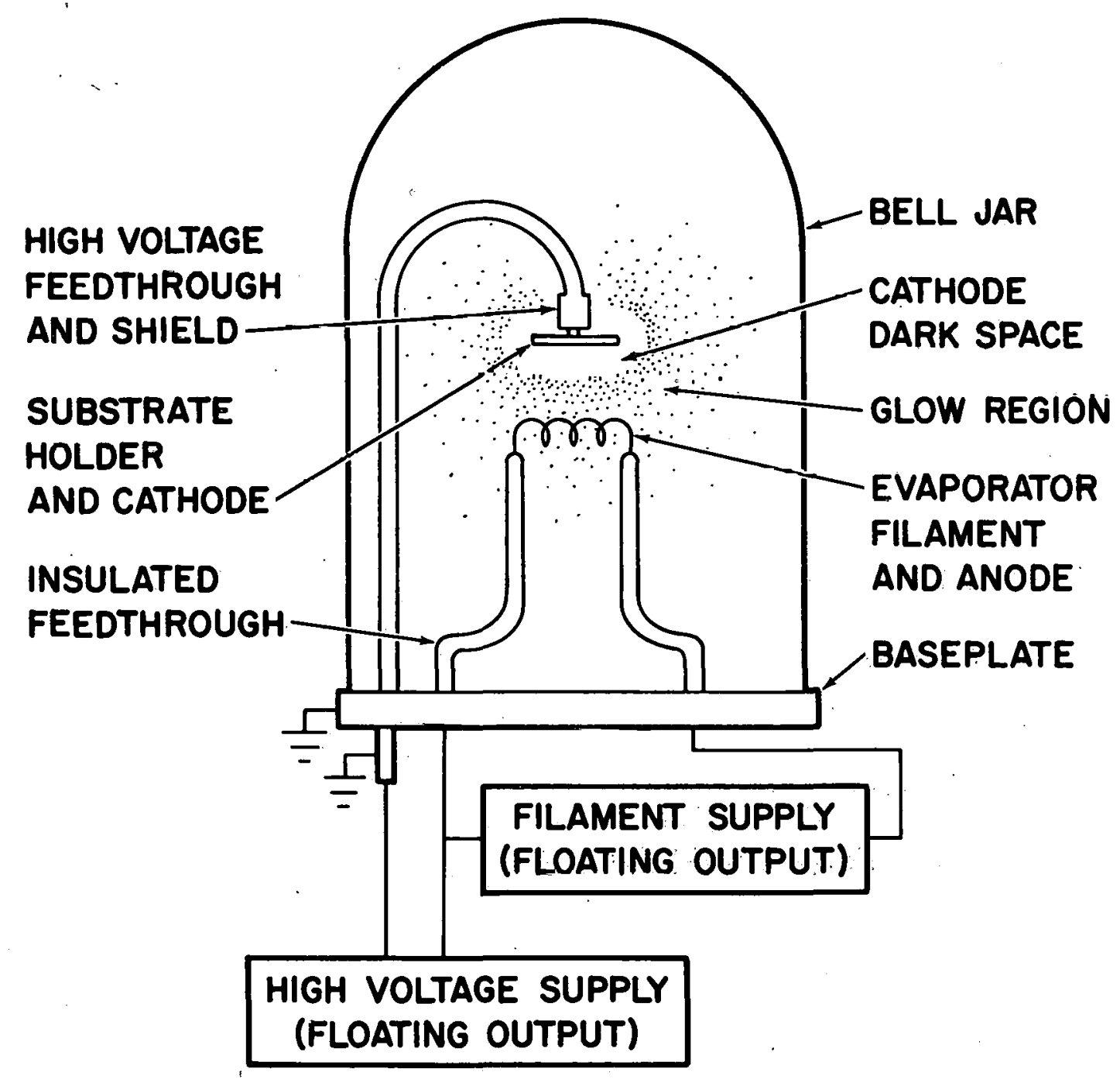

Figure 1. A simple ion plating apparatus using a conventional glass belljar vacuum system. The high voltage feedthrough is shown in Figure 3. 
Small ion plating systems may be made using a short length of glass tubing or glass pipe with an "O" ring or rubber gasket seal on either end. This type of system is often used with a feedthrough collar containing filament feedthroughs, vacuum gages, gas inlet, etc. The upper plate of such a system usually contains the high voltage feedthrough. The whole upper plate should not be made the high voltage electrode unless it can be shielded from ion bombardment since this increases the cathode area unnecessarily. An example is shown in Figure 2 which is a conventional belljar with a section of glass pipe joined to the top. Inside the glass pipe, glass knobs have been placed and ground so that they hold the shield axially symmetric with the cathode. The shield is allowed to float electrically. By using two vacuum seals, the shield may be exposed and grounded. This type of system is particularly adaptable for use as a cold finger cathode as shown in Figure 2.

Since pressure measurements are usually unimportant during ion plating, no special requirements are necessary for vacuum gaging. It is desirable to have a high vacuum gage to determine the pressure before backfilling with gas and thermocouple or pirani gages to monitor foreline and chamber pressure during roughing and deposition.

The gas inlet to the system may be controlled by any one of a variety of calibrated leaks. If the gate valve to the vacuum pump can be throttled, needle valves may be used for a rough leak and the gate valve throttled to give the desired pressure. Usually it is a good idea to keep the gas line under pressure at all times to prevent possible leaks from contaminating the gas. The gas may be introduced anywhere in the chamber, but preferably not in the throat of the gate valve. If a mixture of gases is needed in the process, mixing may be done with separate leak valves or commercially available gas mixtures may be used. Drying and purifying trains may be included in the gas handling system if needed. The leak valve may be controlled by a servo mechanism related to the cathode current to maintain a constant cathode current or to the chamber pressure to maintain a constant gas pressure.

Since the floating filament/anode reaches a voltage of only about 50 volts above ground when some part of the system is grounded, it is usually unnecessary to have high-voltage insulation on the filament transformers. Standard 2 to 5 kva filament transformers having voltage taps of 10 volts, 20 volts, and 40 volts and controlled by autotransformers are generally sufficient for most laboratory requirements. For some applications where the discharge is not related to ground, high voltage insulation of the filament supply may be necessary.

The low voltage-high current anode/filament feedthrough should be insulated from ground to increase the electron flow to the evaporating filament. In most cases, the insulation need only be capable of withstanding 50-100 volts so commercially available feedthroughs are sufficient, possibly with some changes in the seating gasket. Due to the great "throwing power" of the ion plating process, it is often necessary to provide extra protection to the feedthrough-insulator to keep it from becoming covered with the material being deposited. This can be done with shields which physically protect the insulator by providing baffles to the stream of depositing materials. These shields should be made of metal. Glass should be avoided since it has a tendency to build up a surface charge which may arc to ground. Arcing over soft glass or pyrex results in heating and the emission of alkali metal ions present in the glass thus contaminating the system. One side of the filament may be grounded if need be without drastically changing process results. 


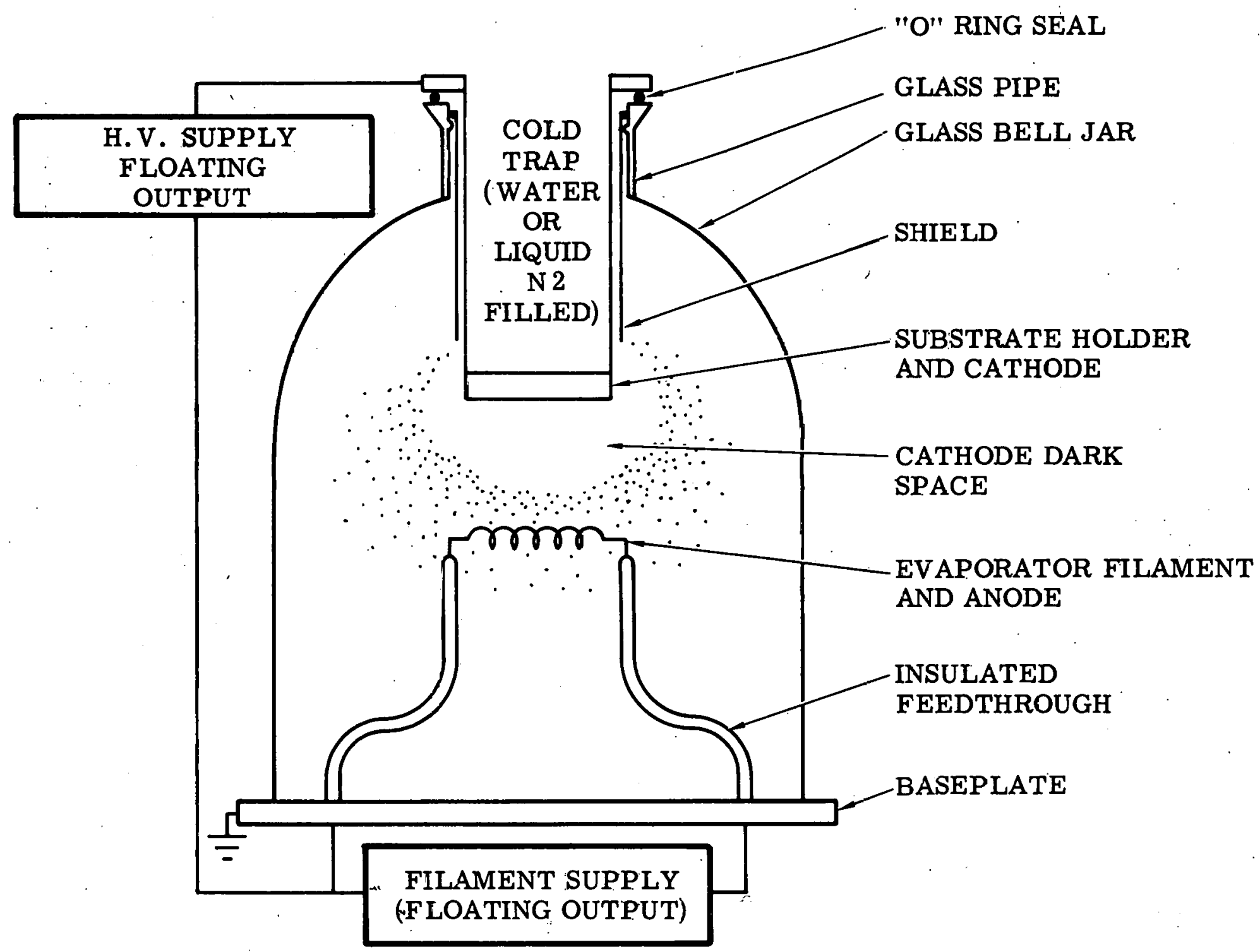

Figure 2. A cold finger cathode made by connecting a section of glass pipe to the top of a conventional glass belljar. The sides of the cold firger are shielded from ion bombardment by the floating shield. 
The high voltage DC glow discharge power supply should have a high reactance transformer to prevent drawing excessive current in case of an arc in the system. There is no need for good regulation or filtering in the power supply. The power supply should be capable of delivering up to $1 \mathrm{ma} / \mathrm{cm}^{2} \mathrm{cathode}$ current density at a voltage in excess of 2500 volts DC. Several commercial glow discharge power supplies having these characteristics are available from suppliers of commercial vacuum equipment. It is preferable to have both sides of the power supply electrically floating but most commercial units have the positive side grounded.

The high voltage feedthrough is the source of trouble more often than any other part of the system due to shorting and arcing. The feedthrough must stand off about 5000 volts from ground and must be shielded in such a way as to prevent metal from depositing on the ceramic insulators. Preventing electrical breakdown in a gas discharge is more difficult than in a vacuum since a momentary arc greatly increases the ion bombardment causing overheating and thermionic emission. The best possible insulator is a separation between electrodes which is less than a cathode dark space width (see Appendix A).

Figure 3 shows a simple high voltage feedthrough which works very well and is used in the setup shown in Figure 1. The rubber or teflon shielded high voltage lead enters the system through the copper tube and is brazed to the threaded portion of the high voltage feedthrough. This and the other braze joints provide the vacuum seal. If the threaded portion of the feedthrough were exposed to ion bombardment, material would be sputtered from the metal onto the ceramic giving a short circuit and the thin metal portion of the feedthrough would heat up giving a temperature gradient which might crack the ceramic. To prevent ion bombardment of this area, a grounded metal shield is positioned less than a cathode dark space width from the ceramic portion of the feedthrough. This prevents ion bombardment of the area and, in addition, physically shields the ceramic from the evaporated material.

Figure 2 shows an arrangement for cooling the substrate by having it in contact with the bottom of a cold finger which acts as the high voltage lead. The cold finger may be filled with water, liquid nitrogen, or may be heated with embedded heaters. To prevent the discharge from occurring along the sides of the cold finger, a metal shield is placed concentrically with, and spaced less than a cathode dark. space width from the cold finger wall. This shield not only prevents ion bombardment of the sides of the cold finger but also prevents metal from depositing on the inside of the glass pipe which is the high voltage insulator. High thermal conductivity materials such as copper and aluminum should be used for the heat sink. The sides of the cold finger should have a low heat capacity and low thermal conductivity, so thin stainless steel is often used. A circulating coolant may be used in the cold finger but it must be deionized to prevent. excessive current leakage and must come through an insulated tube.

Figure 4 shows a high voltage feedthrough for use inside the vacuum system. This feedthrough may be used to connect through any metal plate and is useful in supporting parts in the vacuum chamber.

In all of these designs, care must be taken to keep the ground shields more than a cathode dark space width from the substrate. If this is not done, the field will be distorted by the shield, preventing a portion of the substrate from being ion bombarded. There is evidence that field distortion may occur even if the ground shield is several cathode dark space widths away. All corners and edges of the high voltage feedthrough should be rounded to prevent high field regions which would cause excessive ion bombardment and overheating. Note that the shields on the high voltage feedthroughs are connected to the ground or anode side to keep from increasing the cathode area. 




Figure.3. A simple shielded high voltage feedthrough on a copper tube which may be bent to any configuration. 


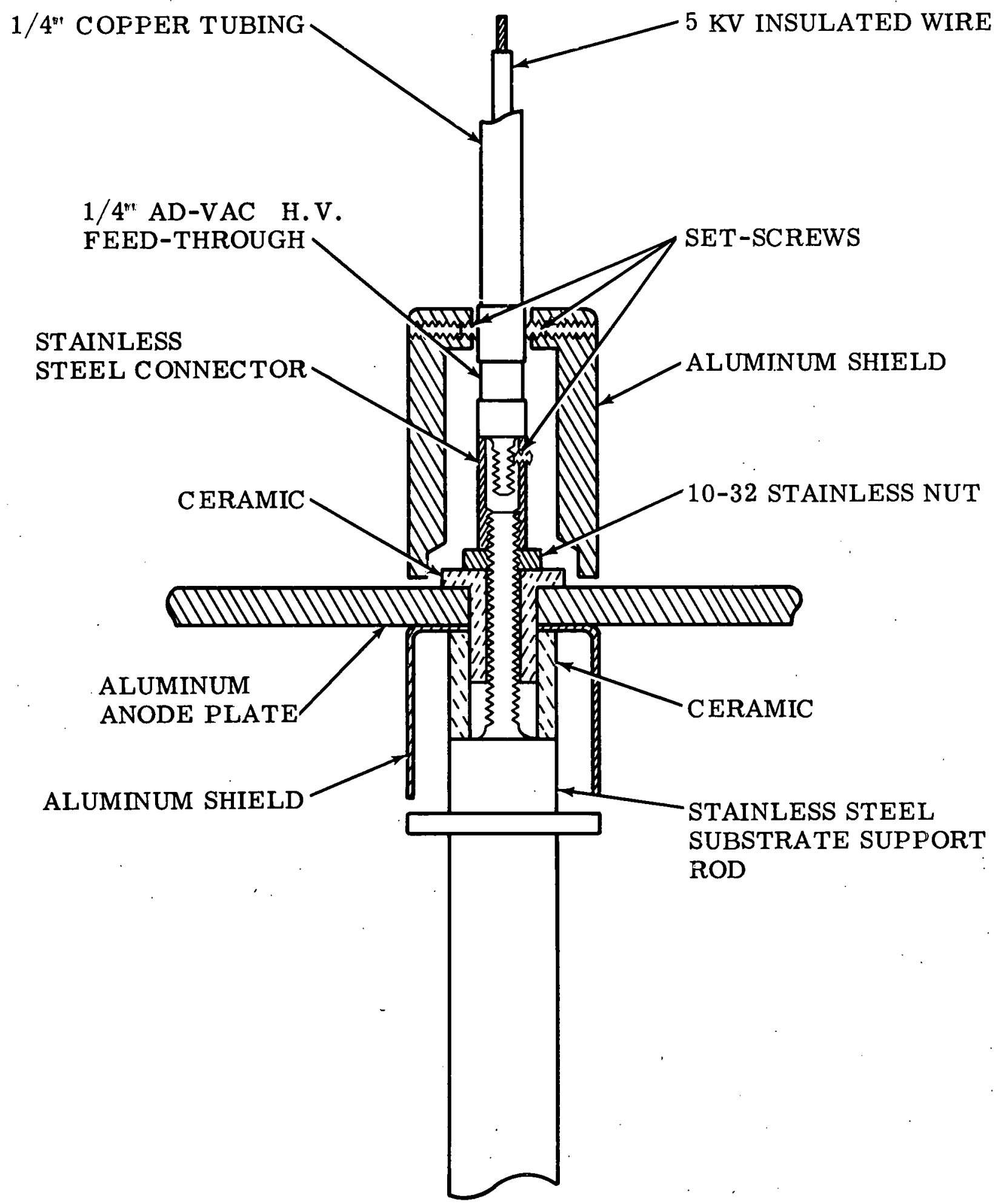

Figure 4. A high voltage connection for use in a vacuum system with a support plate 
Bulk temperature at the cathode may be monitored using a thermocouple but the thermocouple leads must be protected from ion bombardment. This may be done by embedding the leads in the cathode and shielding them in the same manner as the high voltage lead. The temperature indicator, in the form of a millivolt meter or recorder, must be insulated for 5000 volts or more above ground and the operator must treat it as a high potential electrode as it will be at the cathode potential. Leakage to ground from the meter circuit will give incorrect temperature readings.

\section{Evaporation: Sources and Techniques}

Most evaporation sources used in vacuum evaporation may be used in ion plating with the notable exception of focused electron beam evaporation. Since the mean free path of an electron in the gas is short, focused electron beams cannot be used. Unfocused electron beam evaporation from wires and crucibles may be used. When using electron beams for heating it will be found that the emitting filament, which is at a negative potential, will be eroded by ion bombardment and will have a limited lifetime. Any resistively heated source is readily adaptable to ion plating.

Many articles have been written on evaporation techniques ${ }^{\text {(cf.3) }}$ and it is not the intention to review them here but several useful techniques which are not presented elsewhere will be discussed:

Often in coating aluminum on large objects and objects having contours, it is desirable to use long lengths of stranded tungsten filament wire. If a large quantity of aluminum is melted on such a filament, it tends to ball up and roll to some low point where it falls.off. This can be avoided by coiling short lengths of tantalum wire around the tungsten filament at the points from which evaporation is desired. Aluminum clips placed at these points will melt and ball up but will remain on the tantalum coils. This allows a more even distribution of the evaporant.

Another filament source which is quite useful is a stranded filament consisting of strands of refractory metal wire and strands of the material to be deposited. This type of source works well if the evaporant will freely wet the refractory metal. Several combinations which have proven to be particularly useful are aluminum-tungsten, copper-tantalum, and gold-molybdenum. Such stranded filaments may be made in the laboratory using annealed refractory metal wire or can be purchased on special order from most suppliers of tungsten. wire.

In the ion plating process, it is often desirable to evaporate two or more materials. An example is the metallizing of oxides ${ }^{2}$ where an oxygen-active material such as chromium or titanium is desired next to the oxide substrate for adhesion but a material such as copper is desired on the surface for solderability. Several sources may be used in the system as anodes without difficulty. By beginning a new evaporation before the previous evaporation is terminated, an alloy transition region may be formed which enhances adhesion. Another technique for evaporating two materials is to use an alloy or compound such that one constituent will partially vaporize before the other begins. An example of this is the use of a gold-aluminum source material so that, on heating, part of the oxygen-active aluminum will evaporate before the gold begins evaporating. This allows the aluminum to bond to the oxide substrate and the gold to bond to the aluminum. 
Evaporation or sublimation of elements is the most commonly used source for the atoms to be deposited; however, other techniques may be used to supply the film material. The most promising of these is the use of a volatile compound containing the material to be deposited. This compound may be in the form of a gas at room temperature such as tungsten hexachloride or of an easily sublimed solid compound. The compound may then be decomposed in the gas discharge or at the substrate surface.

In the deposition of oxygen active materials by ion plating, such as aluminum on oxide substrates, it has been found that the adhesion of the film is increased either by using several percent oxygen in the gas discharge or by evacuating the system to only $5 \times 10^{-4}$ torr before backfilling with argon. The oxygen apparently aids in the formation of an interfacial region which is conducive to good adhesion. The use of an appreciable amount of reactive gas in the discharge allows the deposition of compounds of some materials much as is done in reactive sputtering (Appendix B).

Positioning of Parts

Holding the parts to be plated requires some precautions. If the part or substrate holder can be suspended from the high voltage feedthrough, a feedthrough such as shown in Figure 3 may be used. If other supports are needed, they must be insulated and the insulators shielded.

Figure 5 shows a holder for a large piece of uranium to be ion plated. ${ }^{4}$ The large disks are the anode/filament holders and the piece is supported by three rods between the anode disks. Two of these support rods have simple shielded insulators to isolate the part from the anode; the third rod is a combination support rod and high voltage feedthrough as shown in Figure 4. The evaporation filaments are positioned around the outside of the part and axially through the holes. All of these filaments are part of the anode. The outside filaments have been formed so as to keep the anode-to-cathode distance great enough so there will be no shadowing of the part from ion bombardment. The axial filaments through the holes have hairpin bends made near the ends so the filaments can be placed under tension when mounted. This prevents expansion and sagging on heating.

Figure 6 shows the arrangement used to plate another uranium piece. In this case, filaments are placed concentrically with the surface to be plated (the curved surface). Only a thin plating is desired on the flat surface so the filaments are positioned below the plane of the flat surface. The piece to be plated is supported from an upper plate which floats electrically. One of the support rods serves as the high voltage lead while the others are insulated from the upper plate. The plate is supported from the baseplate by rods which are insulated at both ends. This allows the central portion of the rods to have auxiliary supports for the evaporator filaments to prevent them from sagging.

If a part is being held by a rod screwed in a threaded hole, it is necessary to provide a channel in the thread so that the cavity under and around the thread may be pumped out. This is not only good vacuum practice but it is particularly important in ion plating since the part will heat up during ion bombardment and greatly increase its outgassing rate. The gas which is released may adversely affect the plating in the vicinity of the hole.

Masking is a problem in ion plating because of the high throwing power of the ion plating process. In order to mask an area, there must be a tight fit between the mask and the part. Even with good masks, 


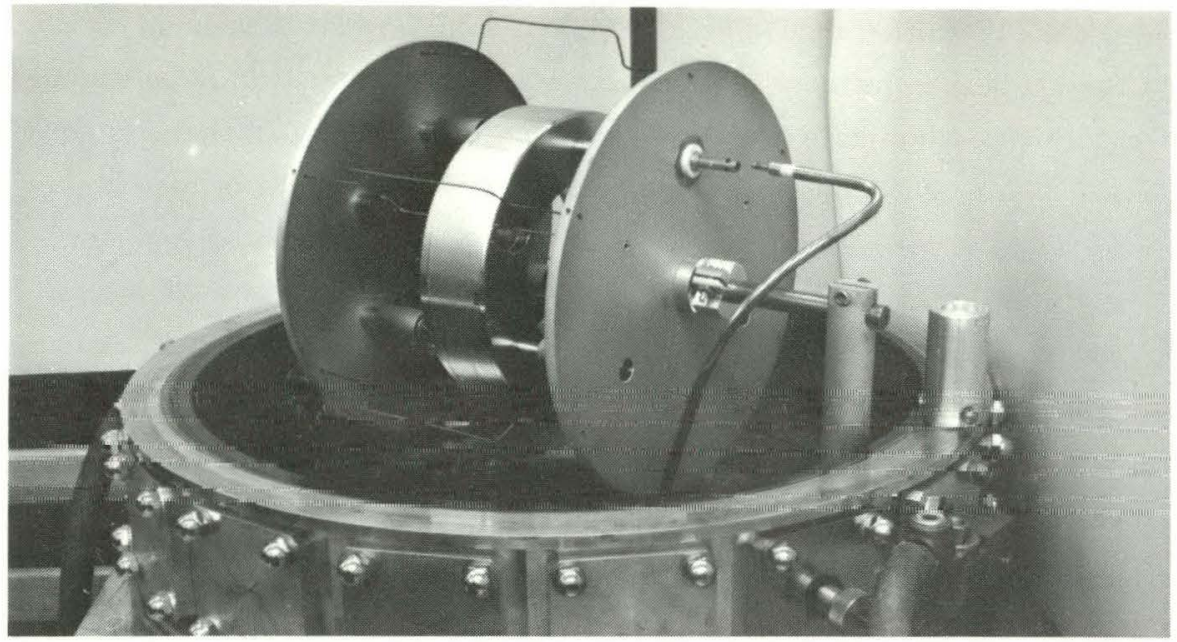

Figure 5. A setup for holding a large piece to be ion plated using shielded rods for support



Figure 6. A setup for holding another large piece showing a different support and evaporation configuration 
it is impossible to get the definition that is obtained when using masks in vacuum evaporation. (The high throwing power of the ion plating process does have the advantage that it is often unnecessary to have special filament configurations to plate in out-of-the-way areas as long as there is no critical plating thickness requirement.) All masks and substrate holders should be made of materials which are not easily sputtered or of materials which will not contaminate the resulting plating. Aluminum has a low sputtering yield and is often used. Titanium has a lower sputtering yield and may be used for low contamination or high temperature purposes (see Appendix B). To avoid contamination, the masks and holders may be plated with the material to be deposited.

Figure 7 illustrates the throwing power of the ion plating process. Copper was deposited on an aluminum tube. The tube is 1-1/2 inch in length and $3 / 8$ inch $\mathrm{I}$. D. The copper was evaporated from a straight stranded filament parallel to the axis of the tube and 6 inches beneath it. Deposition parameters were 20- $\mu$ argon pressure and 5,000 volts with a deposition time of 2 minutes. With this type of configuration, it is impossible to specify the cathode current density. Shown are the thickness-distribution on the outside along the top and bottom, along the top and bottom inside and circumferentially around the outside and inside of the tube $1 / 4$ inch from one end. The thicknesses are in mils and were determined metallographically. Copper could be detected metallographically for 0.5 inch from each end on the inside of the tube.

When ion plating an insulator, using a DC system, it is often desirable to use a grid in front of the insulator. This grid will tend to form a field-free region between the surface of the insulator and the grid allowing any positive charge buildup on the insulator surface to be neutralized by secondary electron emitted from the grid. Grids should have high transmittance (let most of the ions through) and should be made of a refractory material. The separation between the grid and the insulator surface should be small. If the spacing is large, a glow discharge is set up in this region giving excessive heating. It is usually desirable to coat the grid with the material to be deposited to reduce contamination. This may easily be done using the ion plating technique.

Figure 8 shows the cathode used in metallizing the ends of insulating rods. The grid is in the form of a closed-end cylinder which surrounds the part to be plated. If the side of the cylinder is made solid instead of in the form of a grid, a hollow cathode discharge will be set up and the insulator may be overheated (see Appendix A).

\section{Substrate Pretreatment}

Obviously the cleaning which can be accomplished by sputtering is limited; therefore, it is important to clean the part as much as possible before the plating operation. Urganic contaminations may be removed by vapor degreasing, hydrogen firing, etc. Oxides and other barrier layers on metals may be removed temporarily by hydrogen firing, polishing, chemical treatment, etc. Oxide surfaces are effectively cleaned by firing in an oxygen atmosphere. It is important to reduce these contaminating layers to a minimum before plating since they not only affect adhesion ${ }^{5}$ but will increase the porosity of the film if they are present.

During the sputter cleaning portion of the process, organic contamination will be seen to fluoresce and then gradually disappear. For typical ion plating parameters (5000 volts and $\left.0.5 \mathrm{ma}^{2} \mathrm{~cm}^{2}\right)$ organic 


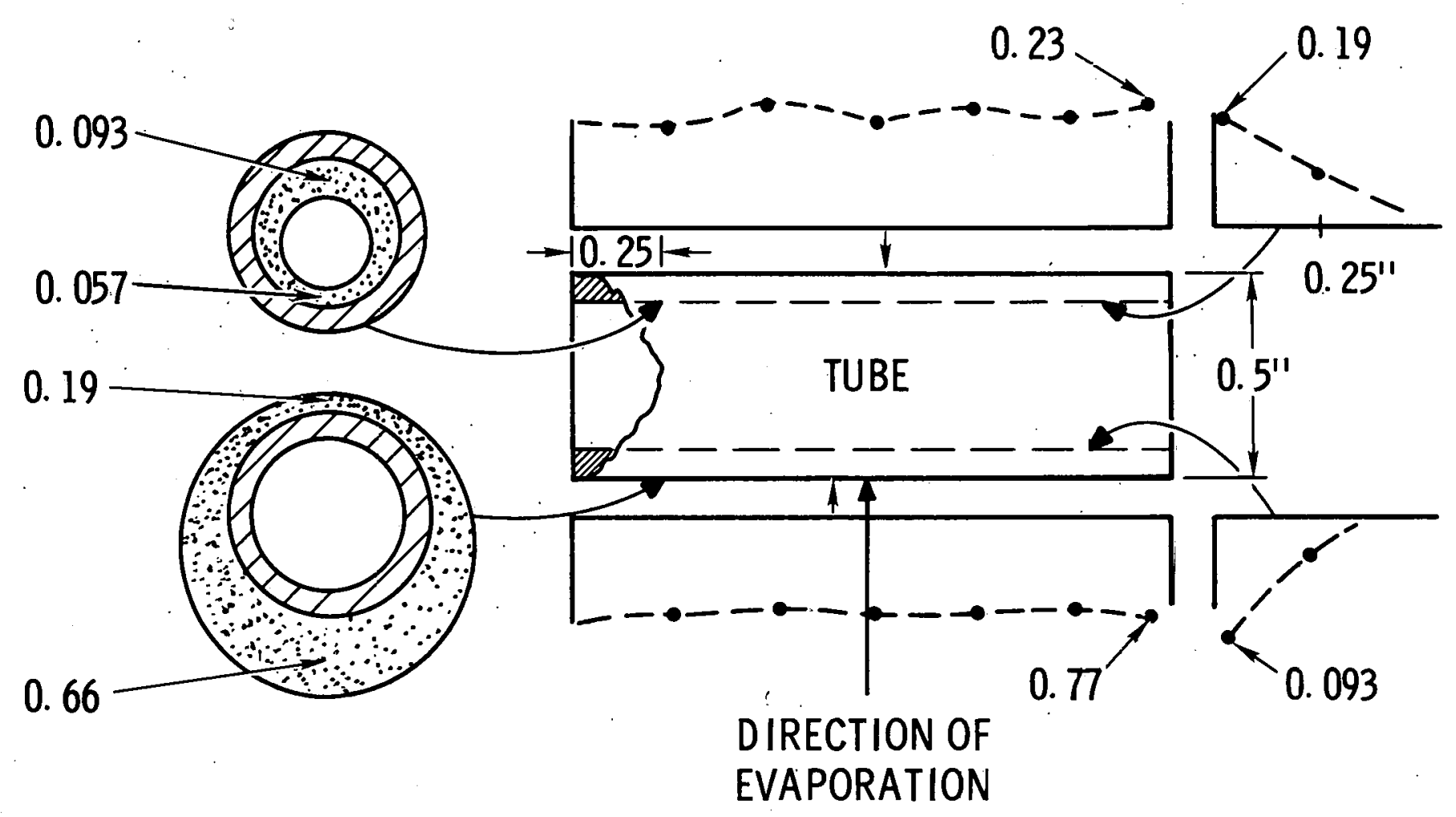

Figure 7. Distribution of copper ion plating on an aluminum tube. Thickness in mils. 


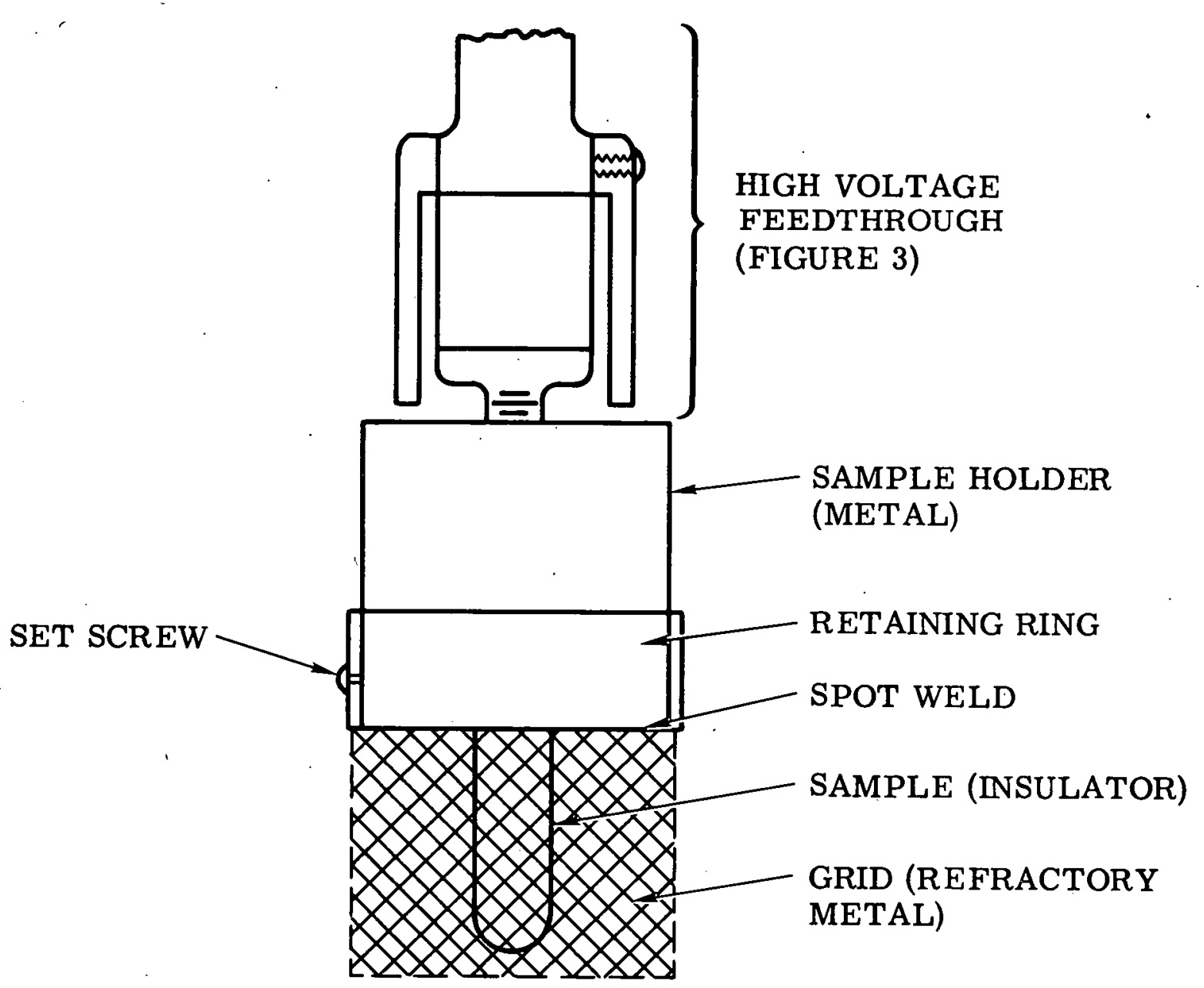

Figure 8. A cathode arrangement used to plate.insulators. The grid is present to prevent charge buildup on the insulator surface. 
contamination will be removed from a metal in 2-3 minutes. To remove the oxide layer such as is found on aluminum and tantalum requires 15-20 minutes of sputtering using the above parameters with a low residual oxygen pressure. Since a glow discharge in an oxygen atmosphere may be used to oxidize many materials, the presence of residual oxygen in the system may actually cause a net buildup of oxides on the surface of an oxygen active material during ion bombardment.

It might be noted at this point that ion bombardment of a surface with inert gas ions often tends to passivate the surface and lessen subsequent corrosion by oxidation. ${ }^{6}$ This has been attributed to the inclusion of the inert gas atoms in the surface lattice decreasing the chemical activity. of the surface. Another possible explanation is that the highly defected surface resulting from ion bombardment may form a coherent tenacious oxide which is to some degree impervious to oxygen and does not scale.

It has been observed that with some metals, it is more difficult to form a good bond between a film and the metal substrate when sputter cleaning is used prior to vacuum evaporation than if it is not used at all. This is probably due to the sputtered surface reacting with residual oxygen in the system and forming a coherent oxide film which inhibits the formation of a diffusion bond. It is important in the ion plating process that the ion bombardment of the surface be maintained until the coating has begun to form.

\section{Process Controls}

One of the principal difficulties in the use of the ion plating process is the lack of monitoring techniques to control film thickness and deposition rates during the process. Film thickness monitoring techniques commonly used in vacuum evaporation, such as quartz crystal oscillators, microbalances, or optical transmission, have only a limited usefulness in a gas discharge. Deposition rate monitors such as momentum transfer vanes and differential ionization chambers likewise are useless. Therefore there is at present no reliable method of controlling film thickness or deposition rate except by a standardization of techniques and procedures for a particular configuration.

A possible method of monitoring may be to measure the intensity of the metal spark spectra in the gas discharge during evaporation and thus to infer the metal ion density. Also sampling and mass analysis of the ions and atoms which strike the cathode would give a direct deposition rate monitoring technique.

\section{Conclusion}

It is hoped that, with this discussion, the investigator who wishes to use ion plating will be able to avoid many of the difficulties frequently encountered. It is also hoped that the elementary discussion of the basic processes involved (given in the Appendices) will allow the user to improve on the process for his particular needs. 


\section{LIST OF REFERENCES}

1. Mattox, D. M. ; Electrochem. Tech. 2, 295(1964)

2. Mattox, D. M. ; J. Am. Cer. Soc. 38, 385(1965)

3. Holland, L. ; Vacuum Deposition of Thin Films, Chapman and Hall, Ltd. (London), 1956

4. Mattox, D. M. and Bland, R. D. ; "Ion Plating of SPRF Reactor Parts," Sandia Corporation Development Report SC-DR-65-530 (1965)

5. Mattox, D. M. ; "Interface Formation and the Adhesion of Deposited Thin Films, " Sandia Corporation Report SC-R-65-852(1965)

6. Moore, Walter J.; Logan, Samuel R., Luther, Lars C. and Brown, Sylvester N.; "Some Physiochemical Effects of Ionic Bombardment of Crystalline Targets," Ion Bombardment: Theory and Application, Gordon and Breach (New York), 1964 


\section{APPENDIX A--GASEOUS ELECTRONICS ${ }^{\text {A1 }}$ \\ Production of Electrons and Ions from Surfaces}

Thermionic emission is the emission of electrons from a heated surface. The production of electrons from an emission-limited surface obeys Richardson's equation:

$$
i=A T^{2} \exp (-\phi / k T)
$$

where $\mathrm{i}$ is the saturation current, $\mathrm{T}$ is the absolute temperature in degrees Kelvin, $\phi$ is the thermionic work function, $\mathrm{k}$ is Boltzmann's constant, and $\mathrm{A}$ is a constant for the material. Some oxides have low thermionic work functions and are used to coat filaments and cathodes for high electron emission.

High electric ficlds may cause electrons and ions to be extracted from a cold surface. This process is called field emission. For field emission to occur, the electric field must be on the order of $10^{8}$ volts $/ \mathrm{cm}$ for electrons, and $10^{10}$ to $10^{12}$ volts $/ \mathrm{cm}$ for ions.

Photoelectric emission occurs when a surface adsorbs a photon of energy and an electron is ejected. An electron is ejected when:

$$
E \leqq h \nu
$$

where $\mathrm{E}$ is the photoelectric work function of the material, $\mathrm{h}$ is Planck's constant and $\nu$ is the frequency of the photon in reciprocal seconds. $E$ is in the range 1 to 6 volts.

When a surface is bo mbarded by high energy particles, electrons may be emitted from the surface. This emission is called secondary electron emission. Electrons are the most efficient particles for causing secondary electron emission. For copper-beryllium alloys bombarded by 300 ev electrons, the secondary electron emission coefficient, $\gamma_{i}$, is about 10 . Ions are much less efficient in producing secondary electrons. The emission coefficients for metal surfaces under ion bombardment are generally less than 1. Figure A-1 gives the emission curves for singly charged ions bombarding a clean tungsten surface. Lighter ions in general cause higher emission coefficients than do heavy ions and multiply charged ions cause higher emission coefficients than do singly charged ions. Oxide surfaces usually have higher emission coefficients than do metal surfaces; this is generally evident in the ion plating process in that as a surface is cleaned of oxide, the current density goes down, at constant pressure, due to the decrease in secondary electron emission (see later section).

Metals having a low work function such as the alkali metals may be ionized by evaporation from a surface having a high work function. This process is called surface ionization. The efficiency, $\Omega$, of this type of ionization is given by

$$
\Omega=\frac{\exp [(-\phi) / k T]}{1+\exp [(I-\phi) / k T]}
$$




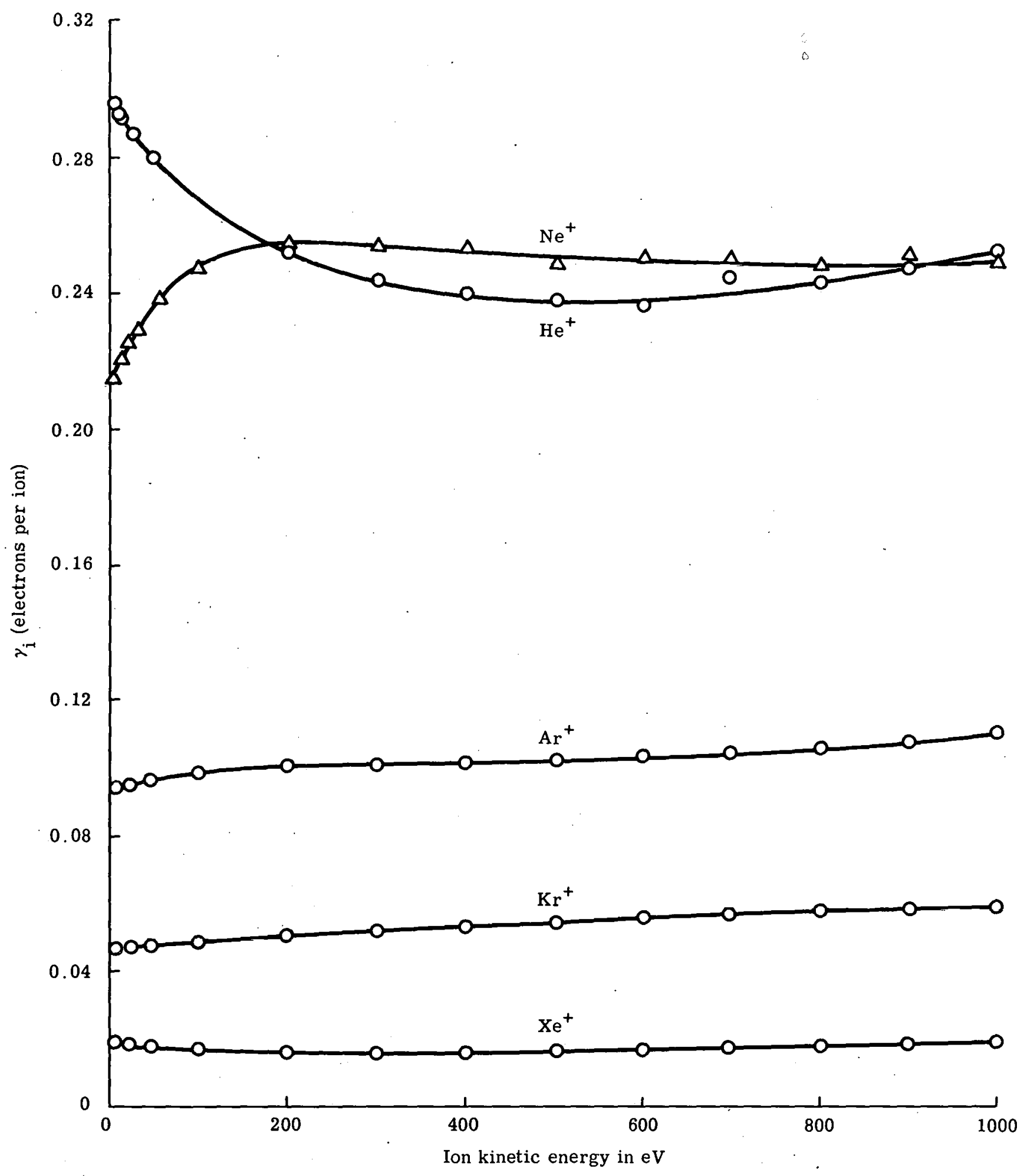

Figure A-1. Secondary emission coefficient, $\gamma_{i}$, for singly charged inert gas ions on tungsten as a function of ion energy: Hagstrum. 
where $\mathrm{T}$ is the temperature in degrees Kelvin, $\mathrm{k}$ is Boltzman's constant, $\phi$ is the work function of the material being evaporated and $I$ is the work function for the surface from which evaporation is taking place, typically $4.2 \mathrm{v}$ for tungsten and $6.0 \mathrm{v}$ for oxidized tungsten. From this it may be seen that ionization of the common metals by evaporation from a hot surface is extremely low. Several commercial ion sources are available using surface ionization to provide an ion beam of materials such as Li, Na, K, $\mathrm{Rb}, \mathrm{Ce}, \mathrm{Ga}$, In and $\mathrm{Th}$. In these sources a neutral atom beam from an oven impinges on a hot tungsten or tungsten oxide surface which acts as the ionizer. An electrostatic deflector is used to separate the ionized from the nonionized species.

Production of Electrons and Ions in a Gas

Thermal agitation may cause collisions between atoms which create an electron-ion pair. This thermal ionization requires gas temperatures of many thousands of degrees Kelvin. Such an ionization process is probably important in high pressure arc discharges but not in glow discharges.

Photoionization occurs when an atom adsorbs a photon of energy causing an electron to be ejected. The lowest energy capable of causing ionization is called the first ionization potential. The first ionization potential is in the range 10 to 25 volts. To remove a second electron, a somewhat higher energy is required called the second ionization potential, and so on.

Ionization by electron-atom collision occurs when sufficient energy is transferred from a high energy electron to an atom during collision to cause the atom to lose an electron. Figure A-2 shows the number of ions formed by an electron traversing a rarified gas with different energies. Note that the most efficient electron energy is in the range 50 to 150 volts. Obviously not all electron-atom collisions result in ionization. The distance which an electron travels between ionizing collisions is called the ionization mean free path.

An atom can only absorb discrete quantities of energy and, if the absorbed energy is not sufficient to ionize the atom, it may excite the atom by raising an electron to a higher energy state. The excited atom may then return to the low energy or ground state by emitting radiation. This radiation produces an excitation spectrum characteristic of the atom. The radiation from an excited ion is called the spark spectrum. If an atom remains in an excited state for an appreciable time, it is called a metastable atom.

The collision of a metastable atom of one kind with an atom of another kind may result in ionization if the excitation energy of the metastable atom is greater than the ionization potential of the second atom. An example of this type of ionization is the use of trace amounts of argon to stabilize a neon discharge.

\section{Gas Discharges}

In any volume of gas, there exist electrons and ions formed by cosmic rays, natural radioactivity, etc. If a DC electric field is applied between two electrodes in this gaseous environment, the electrons and ions are attracted to the anode and cathode, respectively. This type of discharge is called the Townsend discharge and is characterized by a collected current versus voltage curve as shown in 


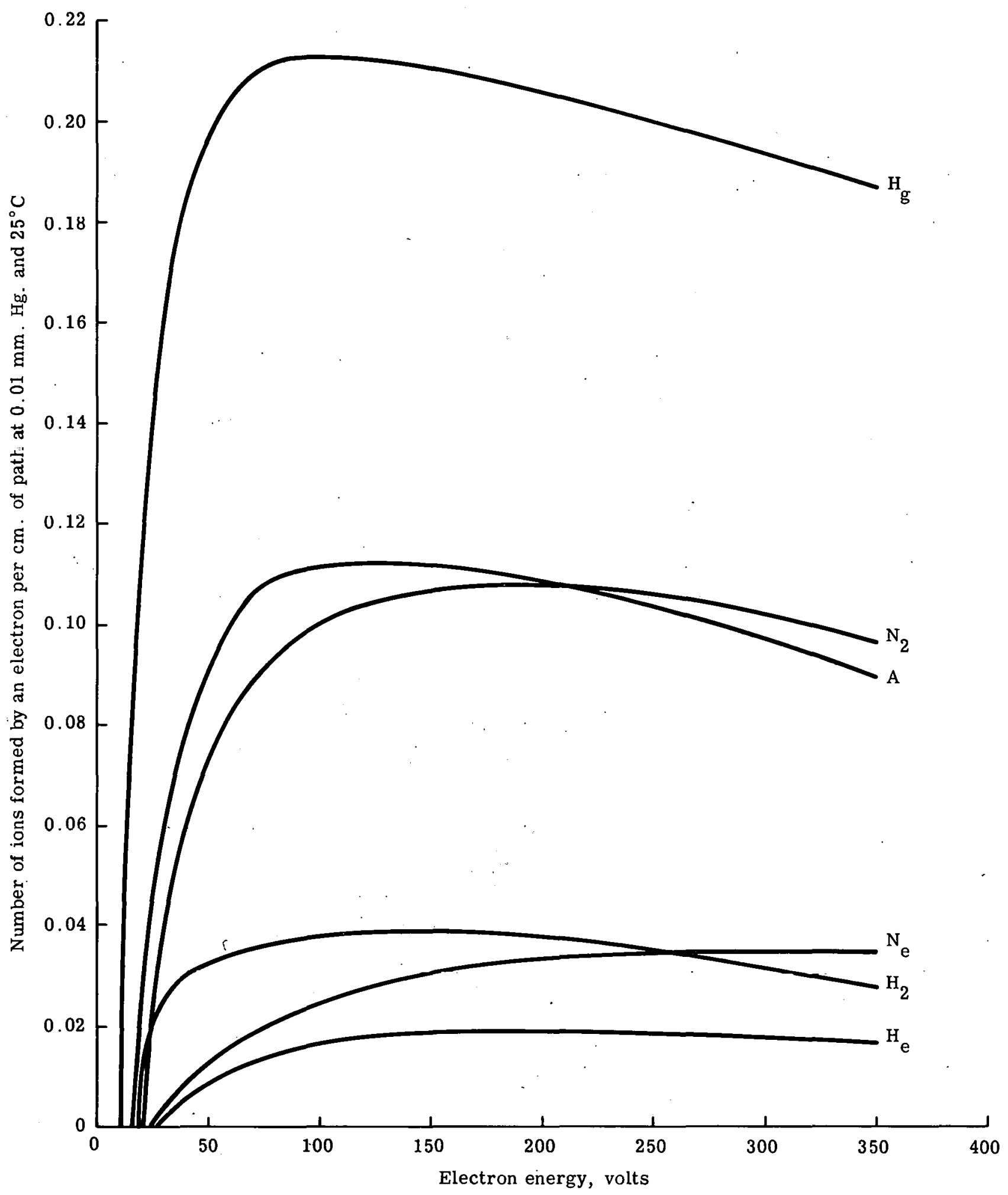

Figure A-2. Formation of ion pairs by electron-atom collision by an electron traversing a rarified gas. Compton, et al. 
Figure. A-3. In region A, some of the ions and electrons which occur by natural process are collected. As the voltage is increased, the fraction collected increases until, in region $B$, the current reaches saturation; i. e., all the charges are collected. As the voltage is increased, the naturally occurring electrons are accelerated to a high enough energy to ionize gas atoms by collision. This increases the charged particle concentration and therefore the collected current, as shown in region C. The Townsend discharge region is characterized by a uniform potential gradient between the electrodes and low collected currents (microamps or less). At some upper voltage limit, $V_{b}$, the Townsend discharge breaks down into a normal glow discharge.

The normal glow discharge is characterized by: (a) the formation of a distinctive light pattern, (b) the establishment of a particular potential and field distribution and (c) an increase in current over that in the Townsend discharge. Figure A-4 shows the characteristics of a typical glow discharge.

The first appearance of the glow discharge is the formation of a small bright spot on the cathode called the cathode spot. This spot has a velvety appearance and a color characteristic of the cathode material. (Often in the ion plating process it is possible to tell from the change in color of the cathode spot when the oxide has been removed from the cathode surface by sputtering.) As the gas pressure is increased, the total current increases but the size of the cathode spot will increase so that the cathode current density (current per unit area on the cathode spot) will remain constant with a constant applied potential. The cathode spot region has a slightly negative space charge.

The comparatively dark region near the cathode is called the cathode dark space or Crooke's dark space and is the region of most of the potential drop in the system. The width of the cathode dark space, $d$, is inversely proportional to the gas pressure, $p$, such that:

$$
\dot{\mathrm{pd}}=\text { constant. }
$$

This constant is voltage dependent in a normal glow discharge at the low voltages but is voltage independent at higher voltages. The constant depends on the gas used in the discharge and has a value of $70 \mathrm{~cm}-$ microns for argon at 1000 volts applied potential. The cathode dark space width represents the number of electron ionization mean free path lengths required for the secondary electrons to produce enough ions to maintain the discharge. Due to the high fields in the cathode dark space and the high mobility of electrons compared to ions, this region has a net positive charge (positive space charge). The normal cathode fall is the lowest voltage across this region at which a. glow is self-sustaining.

The negative glow region is the intensely bright region at the edge of the cathode dark space. This region has the highest temperature in the glow discharge.

The positive column fills most of the remaining space between the negative glow region and the anode. This region is a plasma region in that it contains equal numbers of electrons and ions along with neutral atoms. The number of electrons and ions in this region ranges from $10^{7}$ to $10^{10} / \mathrm{cm}^{3}$ depending on gas pressure, current density and other factors. There is little recombination of electrons and ions in the plasma region since such an interaction requires a third body to carry off the excess energy. The color of the plasma results from the excitation of atoms and ions in the system. The gas temperature in the plasma region is on the order of $10^{4} \mathrm{~K}(10 \mathrm{ev})$. The plasma column may be very long as in the case of neon signs; however, the positive column is not necessary to establish a glow discharge. The anode may be placed in the negative glow region so there is no plasma region. If the anode is placed in the cathode 
N

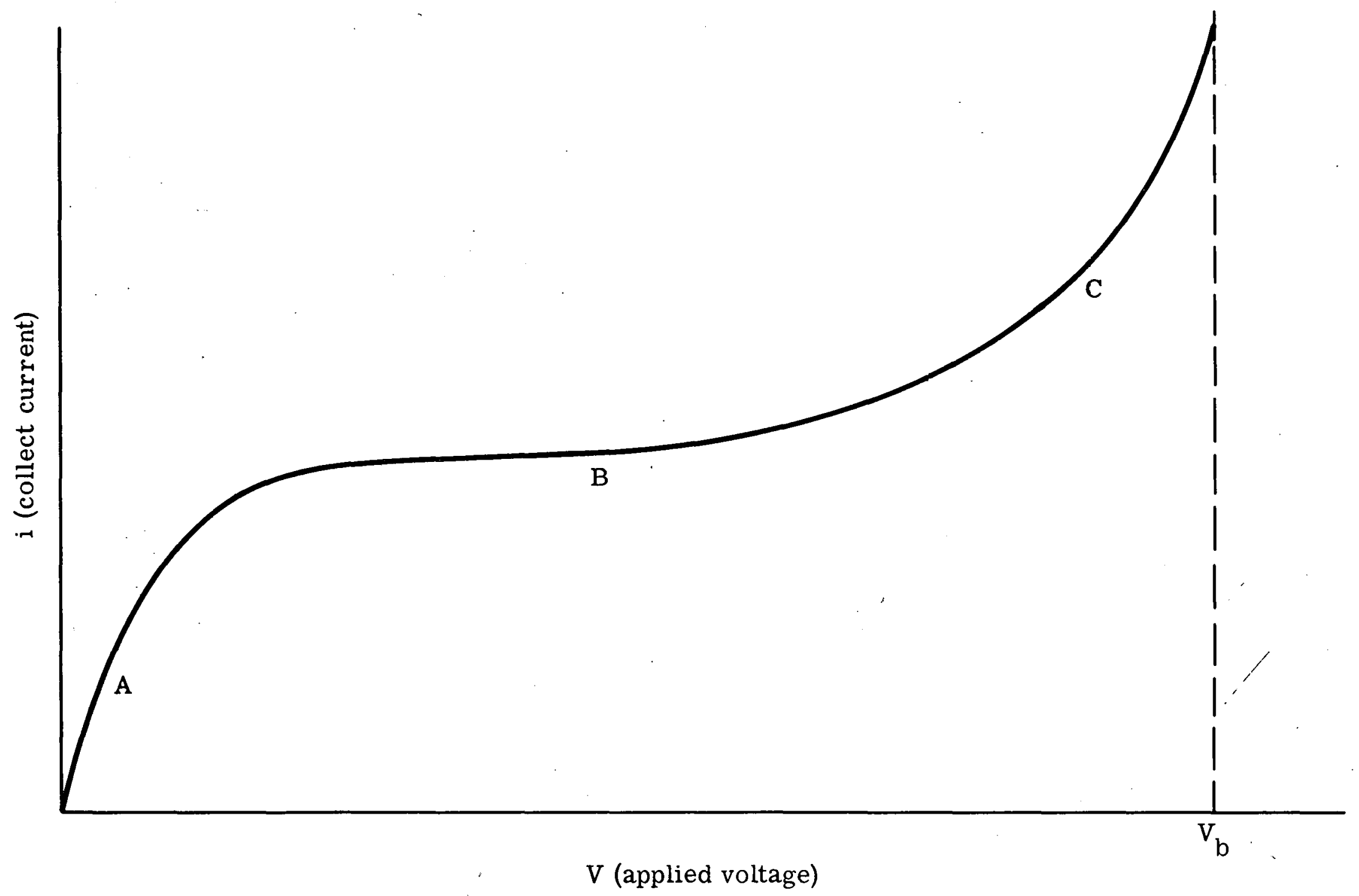

Figure A-3. Townsend Discharge 


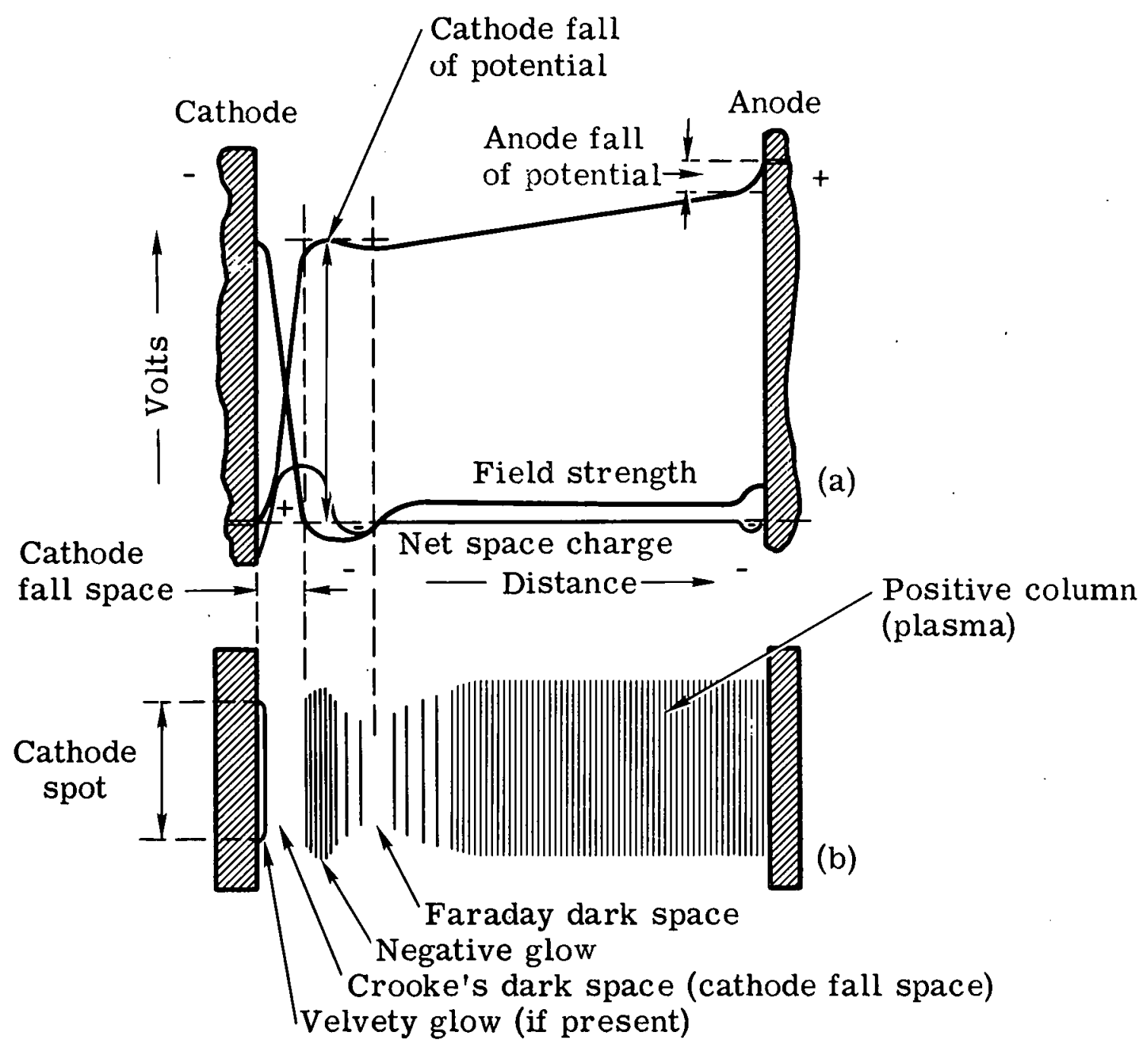

Figure A-4. Glow Discharge Properties 
dark space, no discharge will take place since the emitted secondary electrons do not have sufficient path length to create enough ions to sustain the discharge. This is important in the design of high voltage feedthroughs for the ion plating process.

Next to the anode is found the anode fall region which has a negative space charge. The anode fall potential is approximately the ionization potential of the gas used in the discharge.

In a normal glow discharge at a given potential, the cathode current density over the cathode spot is a constant. As the gas pressure is increased, the total current flow increases by the cathode spot enlarging. On increasing the gas pressure to the point where the cathode spot covers the entire cathode, it is found that to further increase the total current it is necessary to increase the potential across the discharge. The discharge is then called an abnormal glow discharge. The increased potential appears across the cathode dark space and raises the plasma temperature. The ion plating process is usually done in an abnormal glow discharge. The upper limit of the glow discharge is a breakdown into an arc discharge.

The arc discharge is characterized by a small potential drop across the discharge $(<100$ volts $)$ and high current densities (100-1000 amps $\left./ \mathrm{cm}^{2}\right)$. Electrons come primarily from thermionic emission from the cathode. The "plasma" region temperature is high enough to cause ionization by atom-atom collisions. Arc discharges are difficult to stabilize and require consumable electrodes.

Spark discharges are intermittent local arc discharges on the cathode during a gas discharge. In ion plating of materials such as aluminum, spark discharges are often noted when there are oxides on the surface, particularly on points. These tend to heat up, emit electrons and erode away as the surface is cleaned by sputtering.

A glow discharge may be established by impressing a high frequency $(\sim 10 \mathrm{Mc} / \mathrm{sec})$ field on a low pressure gas. In the gas, the free electrons are accelerated back and forth in an attempt to follow the electric field. These electrons collide with the relatively stationary atoms producing ionization by electron-atom collision. The result is a radio-frequency glow discharge.

A glow discharge which relies on secondary electrons for ionization is called a cold cathode discharge. For a cold cathode discharge to be self-sustaining, an equilibrium must be established between the charged particles produced and the particles lost to the electrodes. In the cold cathode discharge, an ion is accelerated to the cathode causing secondary electrons to be emitted. These electrons are then accelerated away from the cathode causing ionization by electron-atom collision.

If the ejected electron ionizes an atom in the cathode dark space region, the resulting ion will be accelerated toward the cathode and the electron from the ion-electron pair will be accelerated toward the anode possibly causing further ionization. If the ionizing collision occurs in the negative glow region where the field is low the electron produced will be unable to cause further ionization.

Since electron bombardment of the anode produces no ions the total measured current, I, in the system is given by

$$
I=I_{i}(1+a)
$$

where $I_{i}$ is the number of ions (or electron-ion pairs) formed in ionizing collisions and a is the secondary electron emission coefficient. It is usually impossible to specify what portion of the measured current 
is due to ions but typical values of secondary emission coefficient for ion bombardment are 0.3 to 1 ; therefore, one half or more of the measured current is due to ions.

The cathode current density depends on the applied voltage, gas pressure, cathode material, type of gas, cathode geometry and electron and ion losses to the walls. The flux to a particular surface area is dependent on the geometry of the cathode. On a sharp edge or point, the electric field is increased and hence the current density is increased. For this reason, sharp edges and points should be avoided in ion plating since they tend to become overheated. In cases where the cathode surface is changing with time, such as being cleaned of oxides or in the ion plating process where another material is being deposited, the cathode current will change by virtue of the changing secondary electron emission coefficient.

By using an auxiliary source of electrons, it is possible to sustain a gas discharge at a pressure below which it would be extinguished if the only source of electrons were from secondary electron emission. This auxiliary source of electrons is usually in the form of a hot cathode which is emitting electons thermionically. 'In this case, the need for production of secondary electrons is minimized. A hot cathode discharge may be established at a pressure of a factor of 10 or more lower than the cold cathode discharge. For example, using argon gas and a cold cathode, a gas discharge can be initiated at about 10 microns of pressure and several hundred volts applied potential. Using a hot cathode emitting a few hundred milliamperes and a voltage of 300 volts DC, the pressure may be reduced to less than 1 micron. With a hot cathode-low pressure discharge, the applied voltage may be reduced to values approaching the ionization potential of the gas $(\sim 20$ volts $)$ and still maintain a discharge.

Another technique of sustaining a low pressure discharge is by the use of a magnetic field. If a magnetic field is applied axially to the path of the electrons, which are emitted or ejected from the cathode, they spiral about the magnetic lines of force. The radius of the spiral is called the Larmor radius, $r$, and is given by

$$
r=\frac{\mathrm{m} \omega_{\perp} \mathrm{c}}{\mathrm{ZeB}}
$$

where $m=$ mass of particle, $\omega_{\perp}$ is the component of velocity perpendicular to the field lines, $c=$ velocity of light, $Z=$ atomic weight, $e=$ charge and $B$ is the magnetic field strength. This spiraling increases the path length of the electron in traversing a given distance from the cathode and thus increases the probability of collision with an atom. The ions which are formed travel in almost a straight line to the cathode since, with their much greater mass, they do not spiral appreciably in the weak fields normally used. Typical magnetic fields used for this purpose are on the order of 300-500 gauss. Use of an axial magnetic field will decrease the pressure needed to sustain a discharge by a factor of 2 to 5 .

A particular type of cathode configuration which is of interest in ion plating is the hollow cathode. In a broad sense, the hollow cathode is any surface which will focus electrons which are ejected from the surface to a point near the surface. This focusing of electrons increases the electron density and thus increases the electron-atom collision probability in this region. The presence of a hollow cathode increases the current density in the vicinity of such a configuration. Figure A-5 shows two types of hollow cathodes of which the cylinder or hole is the most of ten encountered in ion plating. In such a hollow cathode, the increase in current may lead to undesirable consequences such as overheating. 




Figure A-5. Types of hollow cathodə discharges showing focusing and trapping of secondary electrons giving intense ionization near the suriace. 
In the ion plating process it would be desirable to calculate the total energy flux to the cathode surface. This requires that the number and energy of ions striking the surface be known. As we have seen, the number of ions striking the surface is uncertain and their energy distribution is relatively unknown. Even the primary region of ion formation in a glow discharge is uncertain though there is evidence that, in a normal glow discharge, the ions are predominately formed in the cathode dark space, while in an abnormal glow discharge, the ions are formed predominately in the negative glow regions. If there are no energy losses, the energy that an ion acquires in traveling to the cathode depends only on the potential through which it falls. This potential fall depends on where the ion is formed. If it is formed in the negative glow region the ion experiences the total cathode fall potential. If it is formed near the cathode in the cathode dark space, it experiences only part of the cathode fall.

In moving toward the cathode an ion may experience collisions with atoms. In these collisions, the ion may lose only a small part of its energy in an elastic collision which scatters it through a small angle or it may lose considerable energy resulting in a low energy ion and a high energy neutral atom. There may be charge exchange during collision which results in the original thermal atom becoming a low energy ion and the original high energy ion becoming a high energy neutral atom. The charge exchange process may be affected by foreign atoms such as the metal atoms injected by evaporation in the ion plating process.

Davis and Vanderslice ${ }^{A 2}$ have analyzed the energy of ions striking the cathode using relatively high pressure gas discharges and find that the ions striking the cathode have a wide range of energies up to that corresponding to the full cathode fall of potential. The determining factor for each ion species is apparently the ratio between the mean free path for collision and the cathode dark space width. When the mean free path is large, high energy ions predominate. When the mean free path is small, the ions suffer a collision near the cathode surface and are only accelerated through a part of the cathode fall, resulting in predominately low energy ions.

In normal glow discharges, the low energy ions predominate. In abnormal glow discharges, the higher energies become more prominent indicating that most of the ions originate in or near the negative glow region. Figure A-6 shows the energy distribution of $\mathrm{Ar}^{+}$bombarding a cathode surface in an argon discharge. The intensity is in arbitrary units, $V$ is the ion energy, $V_{c}$ is the cathode fall potential, $\mathrm{L}$ is the cathode dark space width, and $\mathrm{l}$ is the mean free path for collision.

$\Lambda$ low pressure, hol cathode discharge would be expected to produce an ion spectrum which has a larger number of high energy ions than a cold cathode discharge since the probability of collision would decrease at the lower pressures. The same would be true when using magnetic fields since the spiraling electron will produce ions nearer to the cathode than if no magnetic field were present thus decreasing the probability of collision for the ion which is attracted toward the cathode.

Because of the high mobilities of the charged particles, a plasma will not sustain a high local field gradient except near a wall or probe which acts as a charge sink. Electrons and ions which are lost to the walls confining the plasma recombine to form neutral atoms. Since the electrons have a higher mobility than do the ions because of their lighter mass, they will be lost to the walls faster than the ions, giving a net negative charge to the wall if it is an insulator. This negative charge will cause a potential drop to develop between the wall and the plasma region, the potential being on the order of 10-20 volts. 


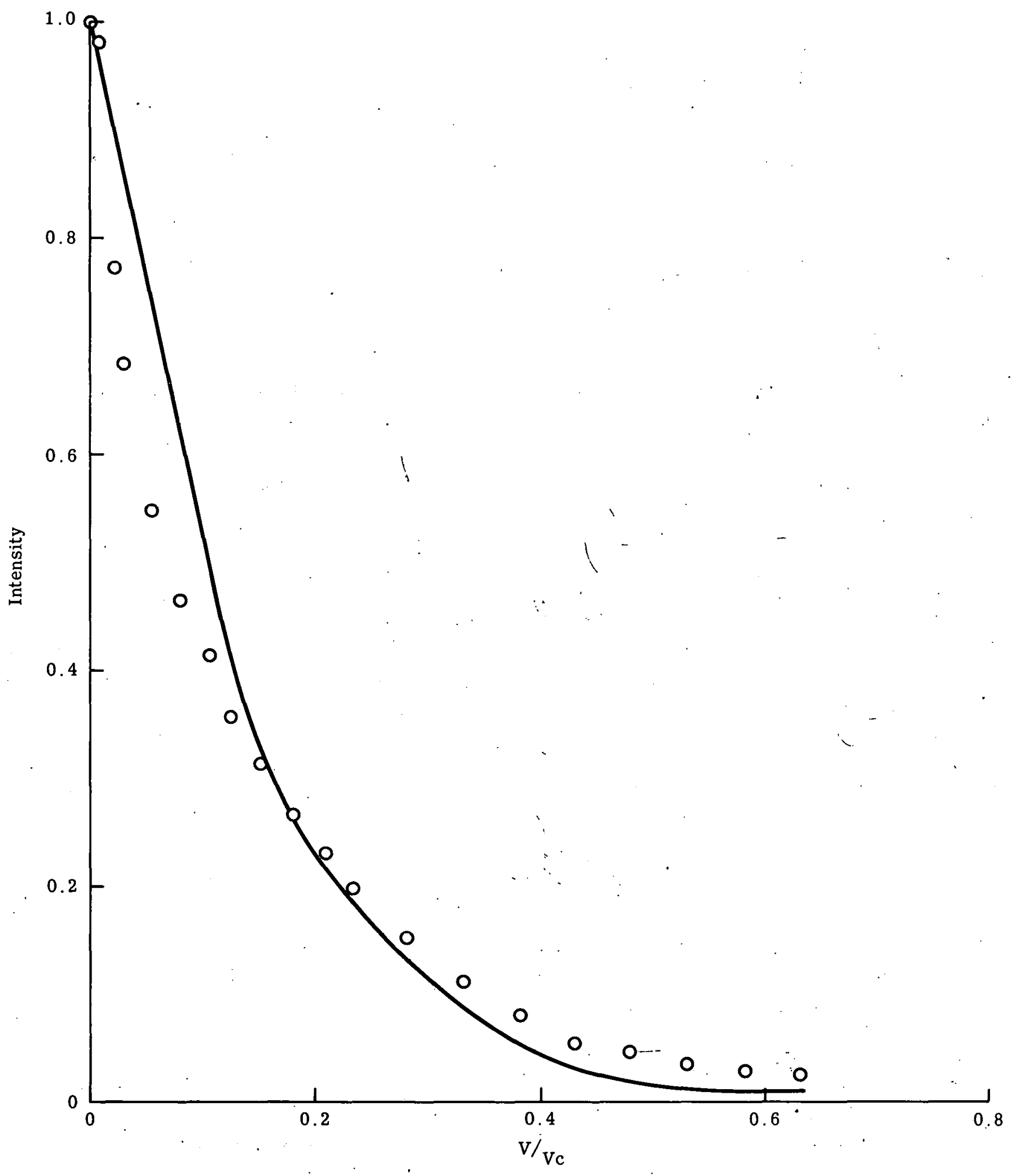

Figure A-6. Energy distribution of $\mathrm{Ar}^{+}$ions at the cathode in a 60 micron argon discharge at 600 volts. Length of the cathode dark space equals $1.3 \mathrm{~cm}$. Ratio of the cathode dark space length to the mean free path for collision equals 15 . Davis and Vanderslice. 
This wall potential will accelerate ions toward the wall and repel electrons giving the region near the wall a positive space charge. This region appears dark compared to the plasma region and is called the wall sheath. The thickness of the sheath is on the order of $1 \mathrm{~mm}$ in a typical discharge and depends directly on $\mathrm{T}^{1 / 2}$ (plasma temperature) and inversely on $\mathrm{N}_{\mathrm{e}}^{1 / 2}$ (density of electrons). The acceleration of the ions to the charged walls is the source of cleaning in the glow discharge cleaning of insulator surfaces (see Appendix B). At equilibrium, there will be no net current flow to the wall, i. e. , there will be an equal number of electrons and ions lost to the wall.

If a conducting probe or electrode is inserted in the plasma region and a potential is applied to it, current will be obtained as shown in Figure A-7. At large negative probe potentials (Region AB) the electrons in the plasma will be repelled from the probe and ions will be attracted to it. The wall sheath is broadened to support the large field imposed by the probe potential. Ions which reach the edge of the sheath are accelerated across the sheath to the probe surface. This current will be space charge limited. Bias sputtering and triode sputtering (see Appendix B) utilize such an electrode configuration.

As the probe potential is made less negative, a few of the high energy electrons begin to reach the probe causing a break, point $\mathrm{B}$, in the $\mathrm{i}-\mathrm{v}$ curve. At point $\mathrm{C}$, the potential of the probe is such that an equal number of electrons and ions are collected giving a net current of zero. The potential at this point is the same as an insulating wall would reach at equilibrium. As the probe is made more positive, the space-charge sheath vanishes and the probe comes to the plasma potential shown at D. The plasma then extends to the probe surface and is undisturbed by the probe. As the probe becomes more positive, the electron current to the probe becomes space charge limited and causes a decrease in the slope of the curve in region EF. Probe measurements may be used to measure the electron temperature and the positive ion density in the plasma.

It has been noted that if an insulating vessel containing a plasma is placed in a radio-frequency field, the luminous portion of the plasma recedes from the walls. Several early authors attributed this to an ability of the radio-frequency field to confine the plasma but it was later shown by Butler that the apparent

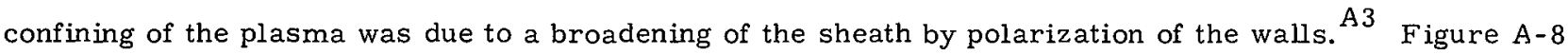
shows a schematic diagram of the system to be considered. On the negative half cycle of the applied radio frequency, a negative charge is induced on the internal wall of the insulator. This negative charge attracts ions from the plasma in an attempt to neutralize the surface charge. The potential across the sheath will be a combination of both the wall potential due to the higher electron mobility and the'surface charge due to polarization. If the applied potential were DC, the surface charge due to polarization would be quickly neutralized and no further current would flow. On the positive half cycle of the impressed radio frequency, a positive charge is induced on the wall and electrons are attracted from the plasma and neutralize the surface charge. Thus the impressed radio frequency results in alternately bombarding the surface with ions and electrons.

Figures A-9 and A-10 show the voltage response obtained by Butler of a plate on the internal surface of the plasma container using the equipment shown in Figure A-8. Figure A-9 shows the response to a $50 \mathrm{kc} / \mathrm{s}$ impressed voltage and Figure A-10 shows the response to a $500 \mathrm{kc} / \mathrm{s}$ voltage. In both cases, the wall goes only slightly positive during the positive half cycle of the radio frequency since the high mobility of the electrons allows them to quickly neutralize any positive surface charge buildup. During the negative half cycle, the walls go negative with a potential which is dependent on the frequency of the impressed 




Figure A-7. Typical current-voltage characteristics for a conducting Langmuir probe in a plasma. $\mathrm{V}_{\mathrm{w}}$ is the potential that an insulating wall would attain in a DC discharge. 


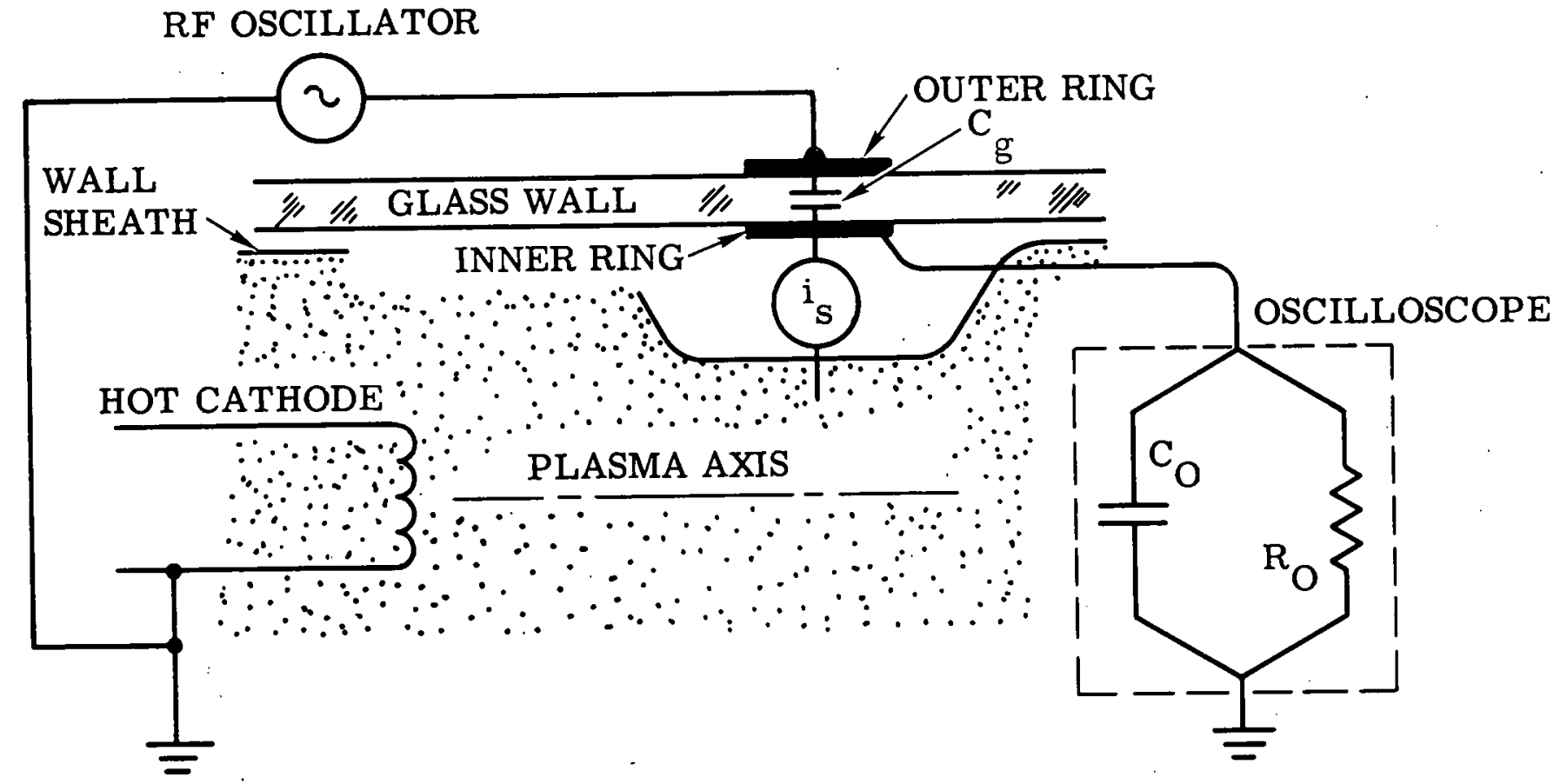

Figure A-8. Schematic representation of the plasma-ring system used by Butler to obtain the data shown in Figures 9 and $10 . \quad \mathrm{C}_{\mathrm{g}}$ is the capacitance of the ring-wall system and $i_{s}$ is the current flow through the sheath. 


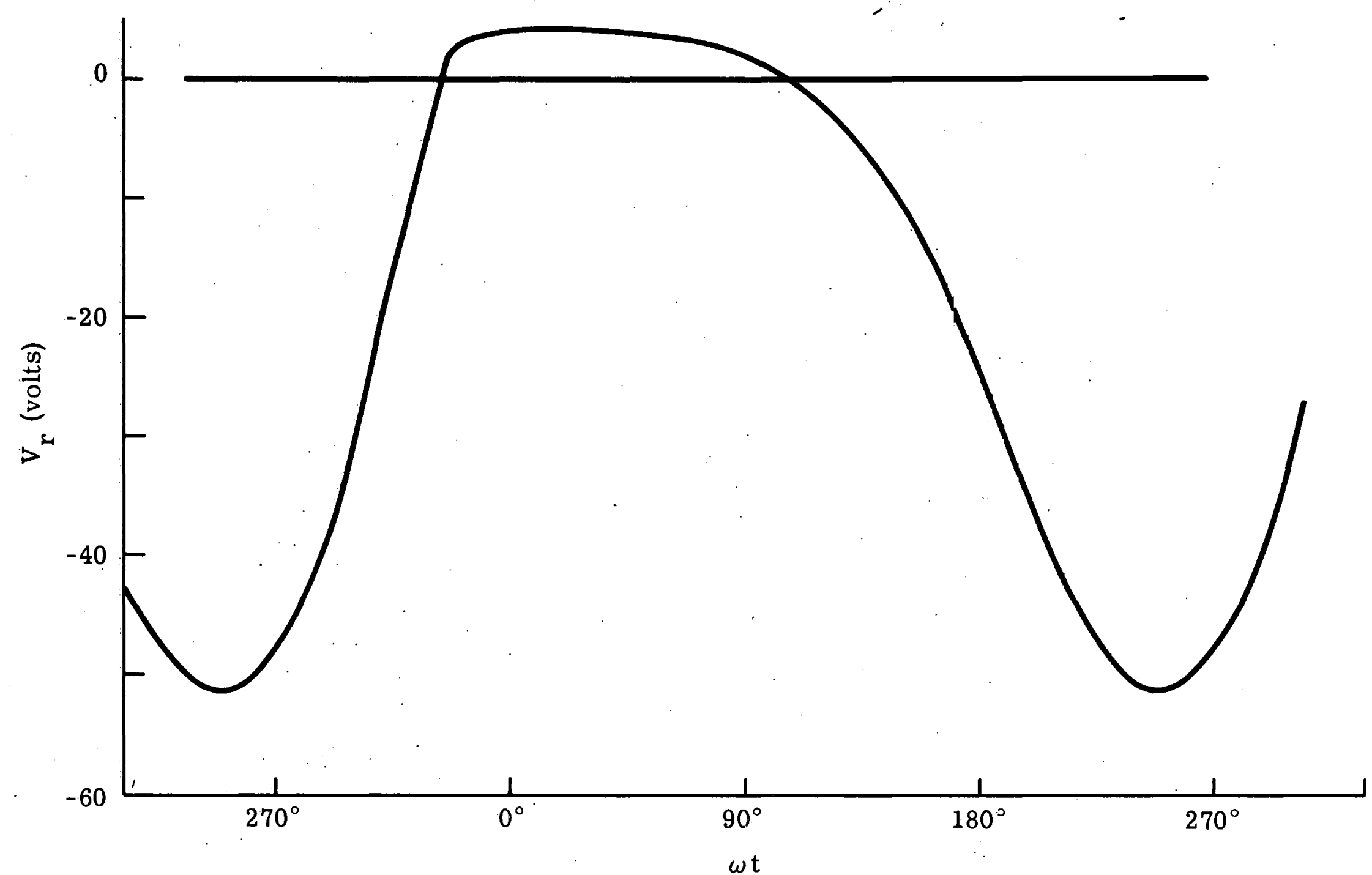

Figure A-9. Voltage response, $V_{r}$, of the inner ring to the impressed voltage which has an amplitude of 200 volts and a frequency of $50 \mathrm{kc} / \mathrm{s}$. Butler. 


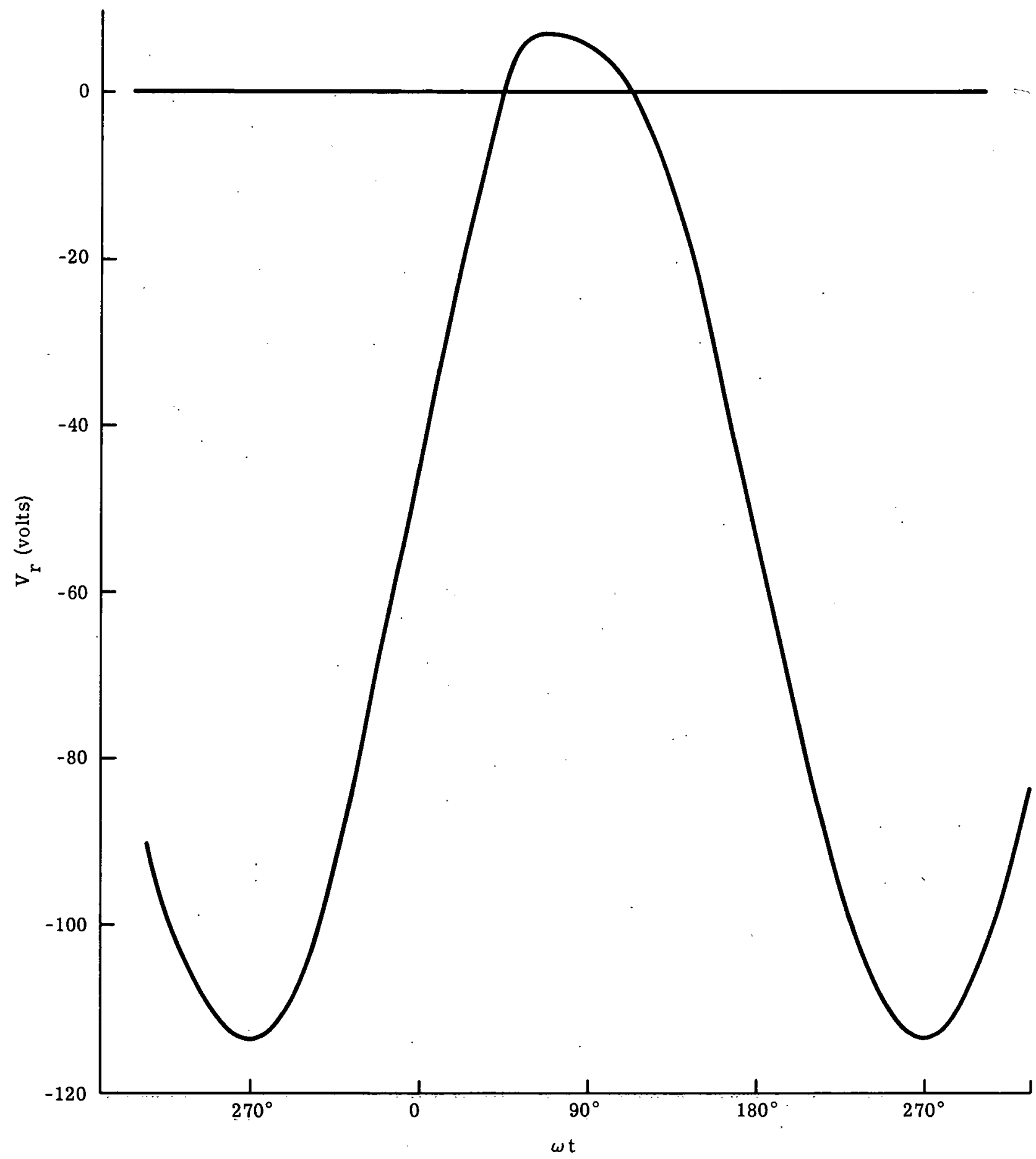

Figure A-10. Voltage response to an impress voltage having an amplitude of 200 volts and a frequency of $500 \mathrm{kc} / \mathrm{s}$. Butler. 
radio frequency. With low frequencies, the ions even with their relatively low mobility can respond to the electric field and neutralize the surface charge buildup. For the higher frequencies, the ions have less chance to move and hence the surface charge buildup is greater, resulting in a higher potential between the walls and the plasma.

$\rightarrow \quad$ The ions which bombard the surface have energies which depend both on the voltage and frequency of the impressed voltage. Higher energy ions will be produced by large peak-to-peak radio-frequency voltages and high frequencies. The spread of ion energies will be a function of the frequency of the applied voltage.

At high frequencies, the wall is kept at a negative potential with respect to the plasma for inust of the radio-frequency cycle. Since this negative wall potential is generally greater than the negative. potential formed with no radio frequency, the sheath is expanded causing the apparent plasma confinement., Stuart and Wehner ${ }^{A 4}$ used this technique in the radio-frequency sputtering of the insulatnrs whish whll be discussed in Appendix B. 
A1. Loeb, L. B.; Basic Processes of Gaseous Electronics, Univ, of California Press, Berkeley, California (1960). Cobine, J. D. ; Gaseous Conductors, Dover Publications, New York, New York, (1958). Guthrie, A., and Wakerling, R. K.; The Characteristics of Electrical Discharges in Magnetic Fields, McGraw-Hill, New York, New York (1949). Penning, F. M. : Electrical Discharges in Gases, MacMillan Co., New York, N. Y. (1957). Spitzer, L. ; Physics of Fully Ionized Gases, Interscience Publishers, New York, N. Y. (1957).

A2. Davis, W. D., and Vanderslice, T. A.; Phys. Rev. 131, 219 (1963).

A3. Butler, H. S.; Plasma Sheath Formation by R. F. Fields, ASTIA-AD260088, Stanford University, M. L. Report No. 820, April 1961.

A4. Stuart, R. V., and Wehner, G. K. ; Jour. Appl. Phys. 33, 2345 (1962). 


\section{APPENDIX B--SPUTTERING}

Sputtering, the removal of material from a surface by particle bombardment, has been observed for many years in the study of gas discharges. Grove ${ }^{\mathrm{BI}}$ (1852) first reported the sputtering phenomenon and Wright ${ }^{\mathrm{B} 2}(1877)$ used sputtering for depositing films. Early workers considered that sputtering was a chemical phenomenon occurring when a reactive ionized gas created an unstable volatile compound at the bombarded surface that vaporized and subsequently decomposed to give a deposit. This process is known as chemical sputtering and does take place in some instances such as in the sputtering of carbon, selenium, arsenic and antimony with hydrogen. ${ }^{\mathrm{B} 3}$

Crookes ${ }^{B 4}$ (1891) gave another explanation to the sputtering mechanism which involved the creation of a localized high temperature region on the surface under ion bombardment with subsequent evaporation. In 1908, Stark ${ }^{\mathrm{B} 5}$ proposed that sputtering resulted from a hard sphere type of collision in the surface region which gave a surface atom enough energy to be ejected. This momentum transfer type of sputtering is called physical sputtering and is apparently the correct explanation for most sputtering, at least when using low energy bombarding ions ( $<10 \mathrm{kev})$.

The momentum transfer type of sputtering is depicted in Figure B-1, which shows how an ion impinging vertically on a surface may transfer enough energy to a surface atom to eject it. For an ion impinging at a low angle to the surface, fewer collisions are needed to eject the surface atom and therefore a larger number of atoms are ejected at a higher average energy. ${ }^{B 6}$ Seeliger and Sommenmeyer ${ }^{B 7}$ have found that for ions incident perpendicularly to a surface with energies of $10 \mathrm{kev}$, the ejected material has an angular distribution which follows Knudsen's cosine law. Wehner and Rosenberg ${ }^{\text {B8 }}$ have shown that for lower energies, the distribution deviates from the cosine law. Figure B-2 shows typical distribution patterns as a function of the energy of the bombarding ion.

At energies below about $50 \mathrm{kev}$, impinging ions lose energy by hard sphere (elastic) collisions and their penetration can be calculated from the Bohr-Neilson equations ${ }^{B 9}$ which have been experimentally verified in the low energy range by Davies and Simms. ${ }^{10}$ When a heavy ion impinges on a material composed of light atoms, the path through the lattice will be in an approximately straight line giving maximum penetration. If a light ion impinges on a heavy atom lattice, the path will be a random walk process giving a lower penetration. The equation for the transfer of energy by hard sphere collision is:

$$
E_{m}=\frac{4 M_{1} M_{2}}{\left(M_{1}+M_{2}\right)^{2}} E
$$

where $E_{m}$ is the maximum energy transfer in a collision,. $M_{1}$ and $M_{2}$ are the masses of the colliding particles and $\mathrm{E}$ is the energy of the incident particle. A typical value for the mean penetration of a heavy ion into a metal lattice is $50 \AA / \mathrm{kev}$ of ion energy. Above $50-\mathrm{kev}$ ion energy, ionizing collisions become important and the hard sphere model no longer holds. 


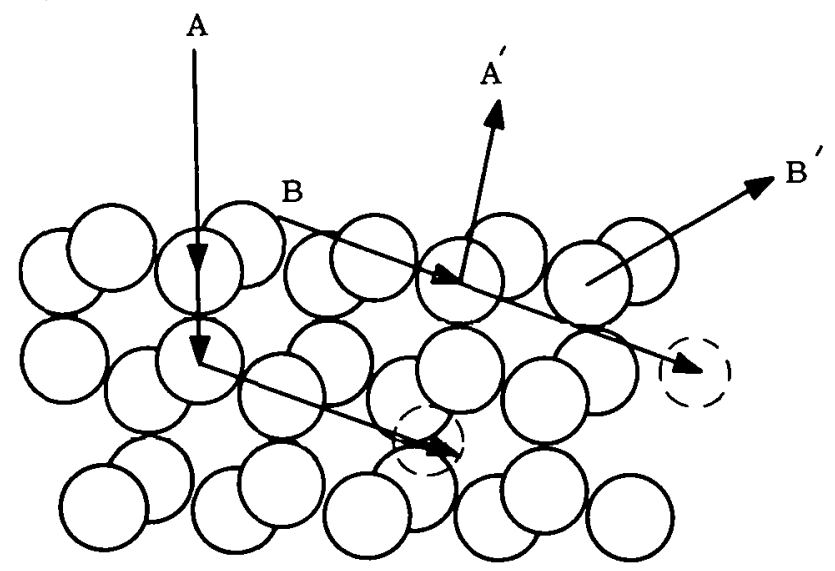

Figure B-1. Sputtering by momentum transfer. Ion from Direction $\Lambda$, which is perpendicular to the surface, causes thc cjection of an atom $A^{\prime}$. Ion from direction $B$, which is at a low angle to the surface, causes ejection of an atom B: View is of a Ge lattice looking in the 1.1.0 direction.

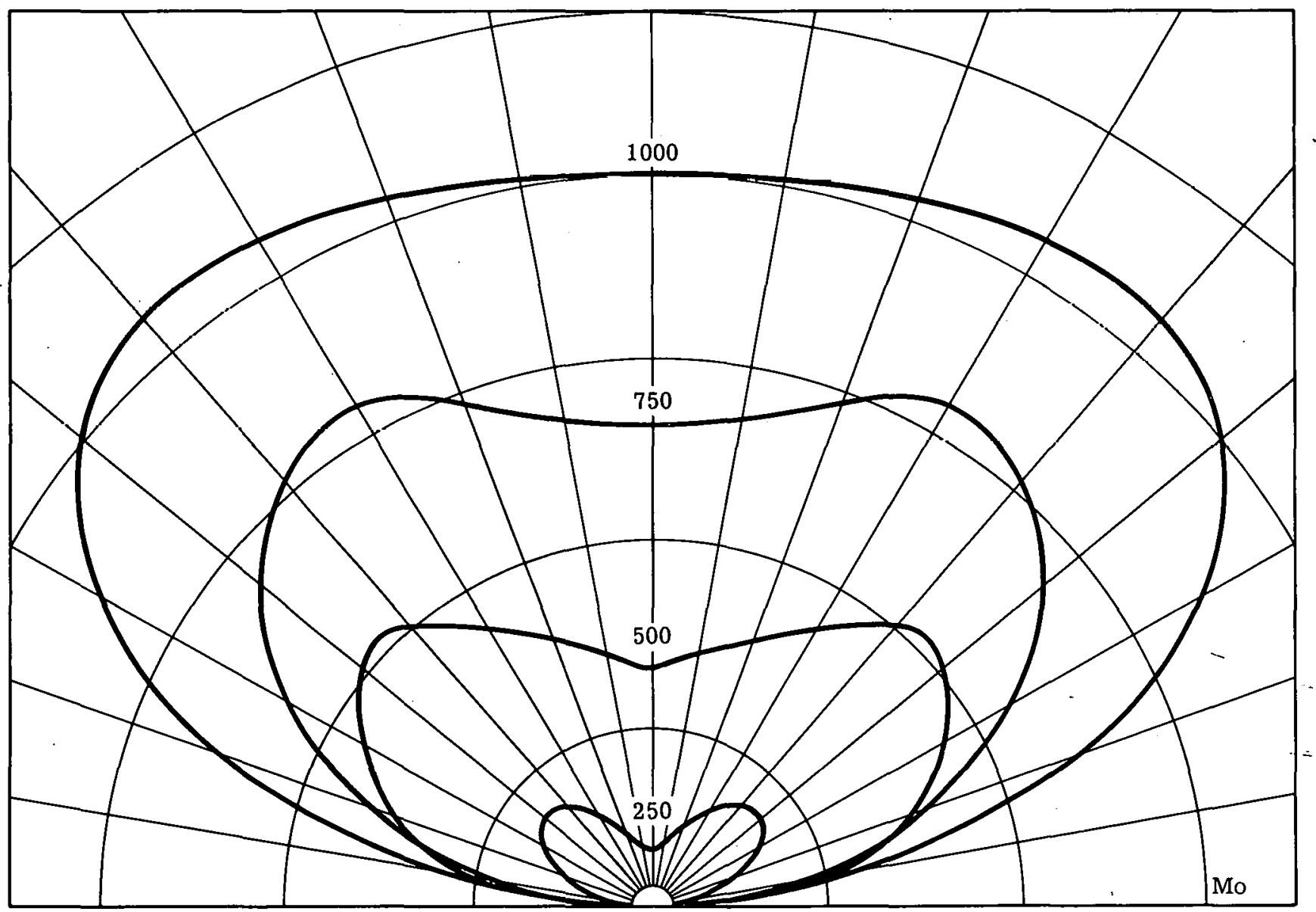

Figure B-2. Angular distribution of material sputtered from a molybdenum target by $\mathrm{Hg}^{+}$ions as a function of ion energy. Wehner and Rosenberg. 
Nelson ${ }^{B 11}$, using electron microscopy, has investigated the fate of high energy inert gas ions, which have penetrated into a metal lattice, and finds the gas precipitates as bubbles in the target lattice.

Almén and Bruce $\mathrm{B}^{\mathrm{B} 12, \mathrm{~B} 13}$ have studied the sputtering yield (number of atoms sputtered per incident ion) using high energy ions (>10 kev) and have obtained curves such as shown in Figures B-3 and B-4. These curves closely agree with a sputtering yield equation given by

$$
S=K \frac{E}{\lambda} \frac{M_{1} \dot{M}_{2}}{\left(M_{1}+M_{2}\right)^{2}} \text { atoms/ion }
$$

where $S$ is the sputtering yield, $E$ is the energy of the impinging particle, $M_{1}$ and $M_{2}$ are the mass numbers of the ion and target atoms, $\mathrm{K}$ is a constant for a certain combination of ion and target material, and $\lambda$ is the mean free path for collision.

Laegried and Wehner ${ }^{\mathrm{B} 14}$ have studied the relative; sputtering yields at lower bombarding energies and find a rapid increase of yield with bombarding energy at low energies $(<200$ ev). Figure B-5 shows typical sputtering yields versus ion energy at low bombarding energies. Table $B-1$ gives the relative sputtering yields for polycrystalline materials as reported by Laegried and Wehner. Sputtering yields depend on the crystal orientation of the surface with close packed surfaces sputtering more slowly than do open structure súrfaces.

The sputtering threshold is defined as the minimum energy which a bombarding ion must have to cause the ejection of an atom. Stuart and Wehner ${ }^{\mathrm{B} 15}$ have studied the sputtering threshold for a number of metals and have found that it is approximately four times the sublimation energy of the material, i. e., 20 to $30 \mathrm{ev}$ for common metals.

Jorgenson and Wehner ${ }^{\mathrm{B} 16}$ investigated the sputtering threshold and yield of insulators by depositing thin films of the insulating material on a Langmuir probe by radiofrequency sputtering (see Appendix $A$ ) and then removing the material by sputtering using DC ion bombardment. By monitoring the probe characteristics, it is possible to determine when complete removal of the insulating material has been achieved. The sputtering yield for $\mathrm{SiO}_{1,6}$ is approximately 0.1 molecule/ion at 100 -ev ion energy (with reference to the plasma) with a sputtering threshold of $16 \mathrm{ev}$. The yield and threshold values of sputtered Pyrex 7740 are similar to those of $\mathrm{SiO}_{1.6^{\circ}}$. Davidse and Maissel ${ }^{\mathrm{B} 17}$ have studied the radio-frequency sputtering yield of bulk insulators by calibrating the radio-frequency sputtering parameters in terms of an equivalent DC sputtering voltage using the sputtering yield of germanium as a standard. Using this technique, they found that the sputtering yield for quartz is 0.5 molecule/ion at $2500 \mathrm{DC}$ equivalent volts and $0.1 \mathrm{molecule} / \mathrm{ion}$ for Lucalux (high density $\mathrm{Al}_{2} \mathrm{O}_{3}$ ceramic) at $2500 \mathrm{DC}$ equivalent volts. No one has as yet determined the species of the particles ejected from an insulator surface by sputtering.

Anderson and Wehner ${ }^{\mathrm{B} 18, \mathrm{~B} 19}$ have shown that, when material is sputtered from a single crystal surface, the material leaves the surface in preferential directions giving a spot pattern to the resulting deposit. These patterns show that there is an anistropic spread of energy from the collision center. Thompson ${ }^{\mathrm{B} 20}$ observed, in the bombardment of gold foils with 0.3 -mev protons, that atoms were preferentially ejected from the back of the foil in close-packed directions giving an ejection pattern. No such ejection pattern has been found in evaporation or sublimation. ${ }^{\mathrm{B} 21}$ 


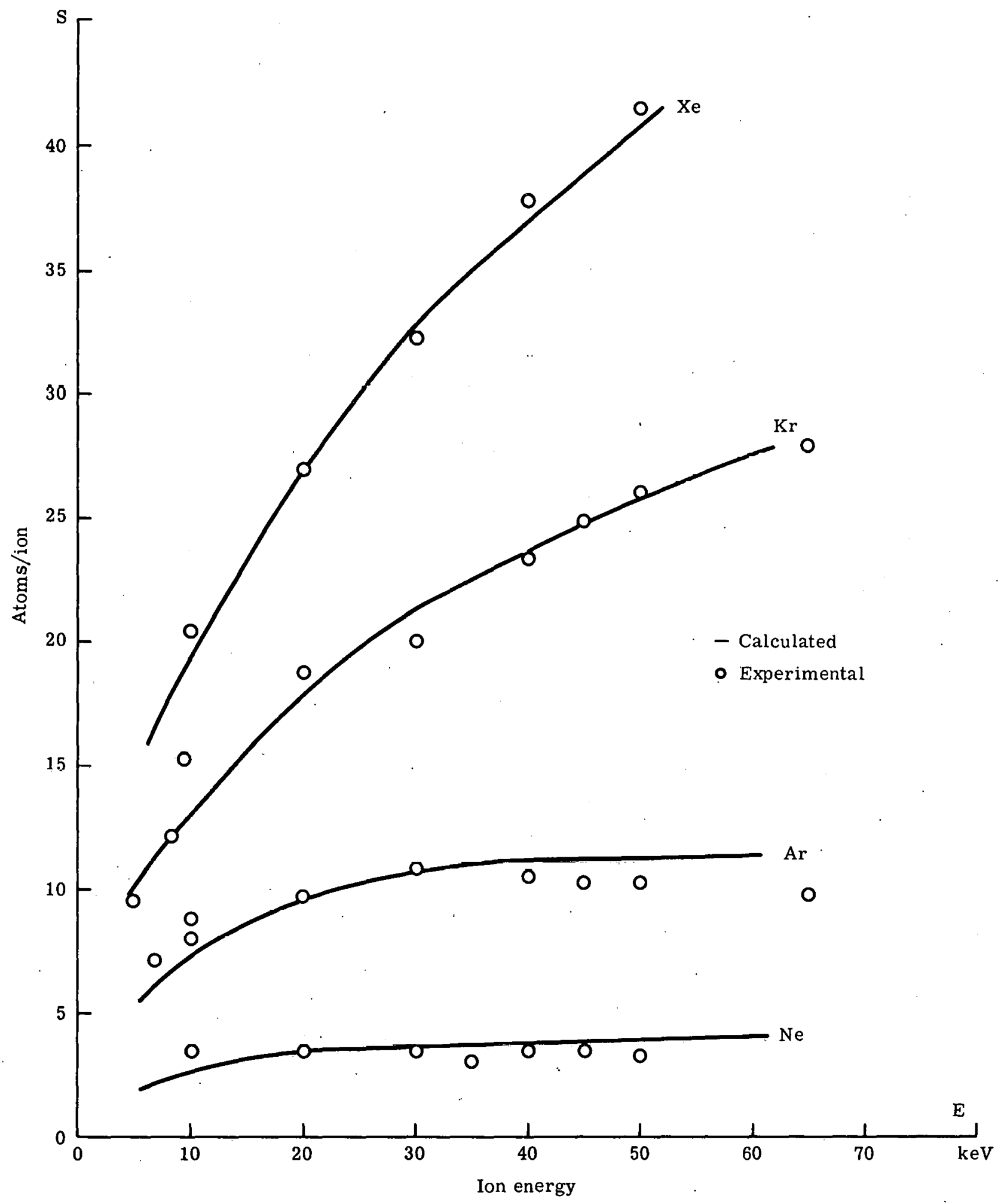

Figure B-3. Sputtering yield as a function of ion energy for gold. Almen and Bruce. 


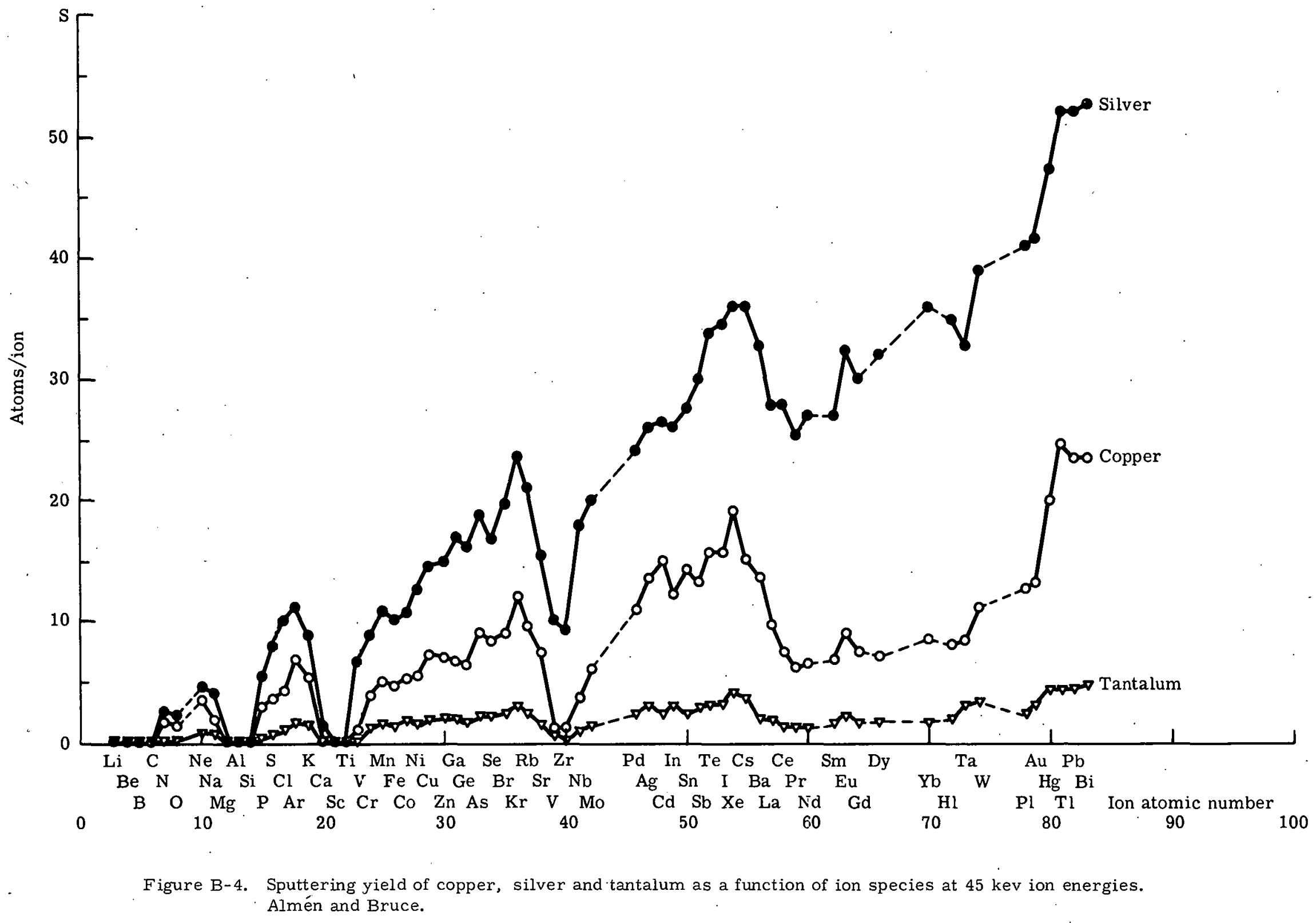






Figure B-5. Sputtering yield of cobalt and tantalum as a function of argon ion energy. Stuart and - Wehner. 


\section{TABLE B-I}

Sputtering Yields for Elements Under $\mathrm{Ar}^{+}$Ion Bombardment (Laegried and Wehner)

\begin{tabular}{|c|c|c|c|c|c|}
\hline Mater & rial & $100(\mathrm{ev})$ & $200(\mathrm{ev})$ & $300(\mathrm{ev})$ & $600(\mathrm{ev})$ \\
\hline $\mathrm{Be}$ & 4 & 0.074 & 0.18 & 0.29 & 0.80 \\
\hline $\mathrm{Al}$ & 13 & 0.11 & 0.35 & 0.65 & 1.24 \\
\hline $\mathrm{Si}$ & 14 & 0.07 & 0.18 & 0.31 & 0.53 \\
\hline $\mathrm{Ti}$ & 22 & 0.081 & 0.22 & 0.33 & 0.58 \\
\hline V & 23 & 0.11 & 0.31 & 0.41 & 0.70 \\
\hline $\mathrm{Cr}$ & 24 & 0.30 & 0.67 & 0.87 & 1.30 \\
\hline $\mathrm{Fe}$ & 26 & 0.20 & 0.53 & 0.76 & 1. 26 \\
\hline Co & 27 & 0.15 & 0.57 & 0.81 & 1.36 \\
\hline $\mathrm{Ni}$ & 28 & 0.28 & 0.66 & 0.95 & 1.52 \\
\hline $\mathrm{Cu}$ & 29 & 0.48 & 1.10 & 1.59 & 2.30 \\
\hline G1 & 32 & 0.22 & 0.50 & 0.74 & 1.22 \\
\hline$Z r$ & 40 & 0.12 & 0.28 & 0.41 & 0.75 \\
\hline $\mathrm{Nb}$ & 41 & 0.068 & 0.25 & 0.40 & 0.65 \\
\hline Mo & 42 & 0.13 & 0.40 & 0.58 & 0.93 \\
\hline $\mathrm{Ru}$ & 44 & 0.14 & 0.41 & 0.68 & 1.30 \\
\hline $\mathrm{Rh}$ & 45 & 0.19 & 0.55 & 0.86 & 1.46 \\
\hline $\mathrm{Pd}$ & 46 & 0.42 & 1.00 & 1. 41. & 2.39 \\
\hline $\mathrm{Ag}$ & 47 & 0.63 & 1.58 & 2.20 & 3.40 \\
\hline $\mathrm{Hf}$ & 7.2 & 0.16 & 0.35 & 0.48 & 0.83 \\
\hline $\mathrm{Ta}$ & 73 & 0.10 & 0.28 & 0.41 & 0.62 \\
\hline W & 74 & 0.68 & 0.29 & 0.40 & 0.62 \\
\hline $\operatorname{Re}$ & 75 & $0: 10$ & 0.37 & 0.56 & 0.91 \\
\hline Os & 76 & 0.057 & 0.36 & 0.56 & 0.95 \\
\hline Ir & 77 & 0.12 & 0.43 & 0.70 & 1.17 \\
\hline $\mathrm{Pt}$ & 78 & 0.20 & 0.63 & 0.95 & 1.56 \\
\hline $\mathrm{Au}$ & 79 & 0.32 & 1.07 & 1.65 & $2.43(500)$ \\
\hline Th & 90 & 0.097 & 0.27 & 0.42 & 0.66 \\
\hline $\mathrm{U}$ & 92 & 0.14 & 0.35 & 0.59 & 0.97 \\
\hline
\end{tabular}


Veksler ${ }^{\mathrm{B} 22}$ using $\mathrm{Cs}^{+}$ions and Stuart and Wehner ${ }^{\mathrm{B} 23}$ using inert gas ions and $\mathrm{Hg}^{+}$ions have shown that the average energy of sputtered atoms is greater than $5 \mathrm{ev}$ for low energy ion bombardment $(\sim 1000 \mathrm{ev})$. The energy distribution for the sputtered atoms shows a high energy tail which extends to 100 ev or greater. Figure B-6 shows typical energy distribution curves of copper ejected by $\mathrm{K}+{ }^{+}$ions. Figure B-7 shows the average energy as a function of bombarding ion energy. Stuart and Wehner have also noted a marked dependence of the ejected particle energies on the angle of ejection with the higher energies and denser deposits corresponding to directions parallel to close-packed planes in the crystal. They also find that the ejection energies decrease when using lighter ions and that the dependence of the ejection energy on ion energy is strong below $200 \mathrm{ev}$ and weak above $1000 \mathrm{ev}$. The weak dependence above $1000-\mathrm{ev}$ ion energy may be attributed to the penetration of the bombarding ion into the target lattice.

Since the evaporation theory gives only low cnergy ( $<1 \mathrm{ev}$ ) nondirectional atoms, it. is not acceptable for the explanation of sputtering at low bombarding energies. Thus the momentum transfer theory appears

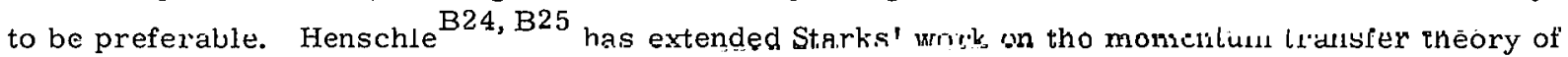
sputtering by incorporating the focusing mechanisms proposed by Silsbee ${ }^{\mathrm{B} 26}$ and has accounted for the aturn ejection patterns.

Temperature does affect sputtering yields in some cases. Carlston, Magnuson, Comeaux, and Mahadevan ${ }^{\mathrm{B} 27}$ found no change in yield for face-centered cubic polycrystalline $\mathrm{Cu}$ and $\mathrm{Al}$ while the body-centered cubic polycrystalline Mo, $\mathrm{W}$ and $\mathrm{Ta}$ showed approximatcly a 30 percent increase in yield in raising the temperature from $350^{\circ}$ to $1000^{\circ} \mathrm{K}$. A Mo(100) crystal face showed no change in yield over the temperature range while a $M o(110)$ face showed a 12 percent increase. A Cu(110) face showed no change over the temperature range and a $\mathrm{Cu}(111)$ face showed a decrease of 24 percent for $2-\mathrm{kev} \mathrm{Ar}{ }^{+}$ion bombardment which may have been due to faceting of the surface.

Recent work by Nelson ${ }^{\mathrm{B} 28}$ has shown that at very high bombarding energies and elevated target temperatures, evaporation from regions resembling thermal spikes may be important. This is to be cxpected since the high energy ions will dissipate most of their energy well below the surface.

In addition to sputtering, ion bombardment produces defects in the surface of the material being bombarded. Using low energy electron diffraction, Jarnhson and Wchner ${ }^{B 29}$ litve studied the ion bombardment of germanium surfaces. The lowest ion energy which caused damage to the surface (damage threshold energy) was $20 \mathrm{ev}$. Ion energies of $100 \mathrm{ev}$ were capable of completely destroying the surface structure after a dosage of $10^{16}$ ions $/ \mathrm{cm}^{2}$ while $1-\mathrm{kev}$ ions completely disrupted the surface after $10^{14}$ ions $/ \mathrm{cm}^{2}$. Energies of less than $100 \mathrm{ev}$ never completely extinguished the germanium surface structure.

Ion bombardment damage to gold films has been studied by Ogilvie, Sanders and Thomson ${ }^{\text {B30 }}$ using transmission electron microscopy. The damage caused by bombardment was found to depend markedly on the ion mass and energy and to a lesser extent on the ion flux density and crystal orientation. There was a threshold energy for damage $(20 \mathrm{ev})$ below which no damage was detectable and its values for neon, argon, and xenon, but not helium, are consistent with a model in which a simple collision at the surface creates an interstitial atom below the surface. The disruption of the surfacel during ion bombardment may affect the nucleation and diffusion of the material deposited during ion plating. 


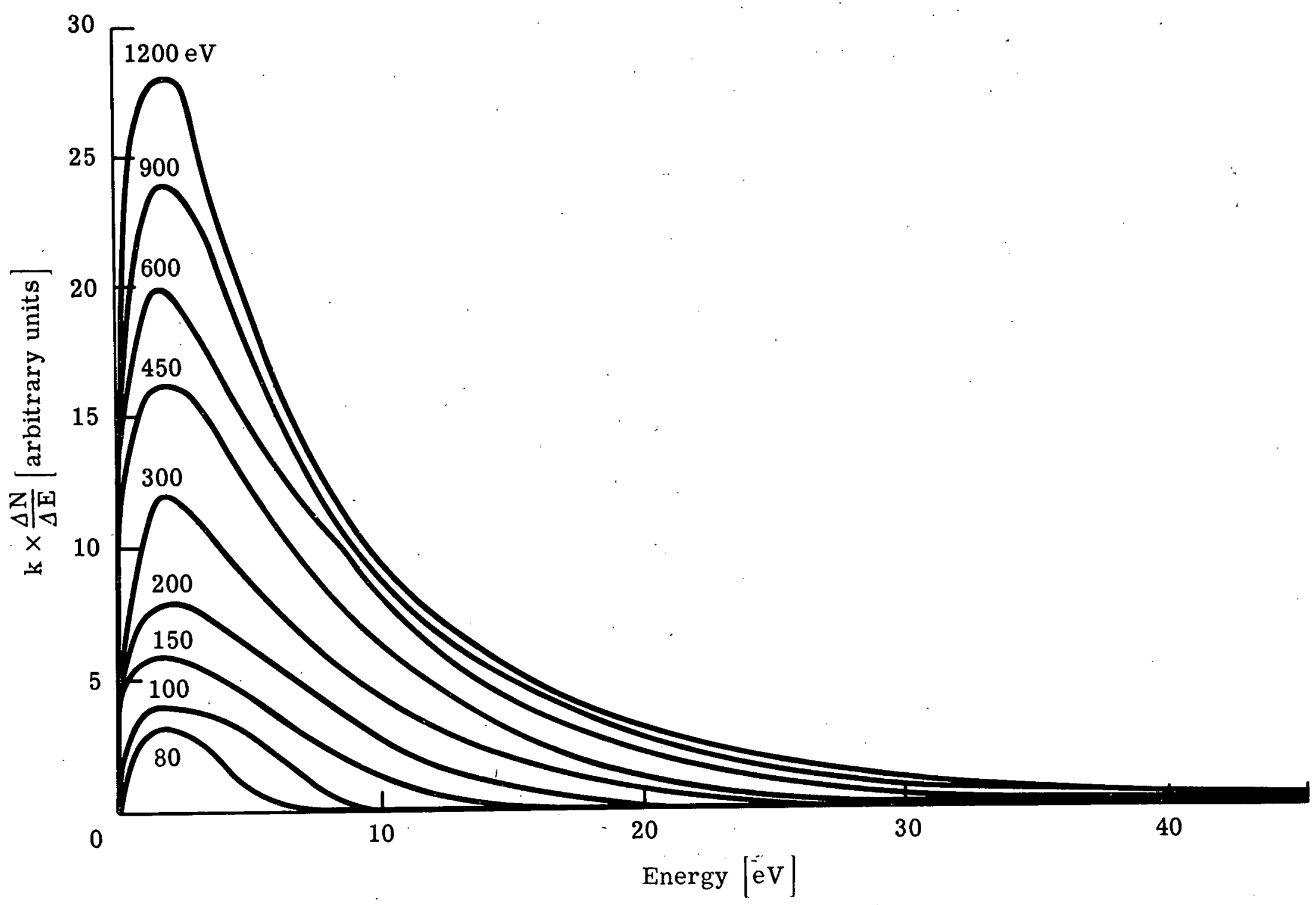

Figure B-6. Energy distributions of copper atoms ejected normal to the surface from a copper (110) surface by $\mathrm{Kr}^{+}$ions having various energies. Stuart and Wehner. 


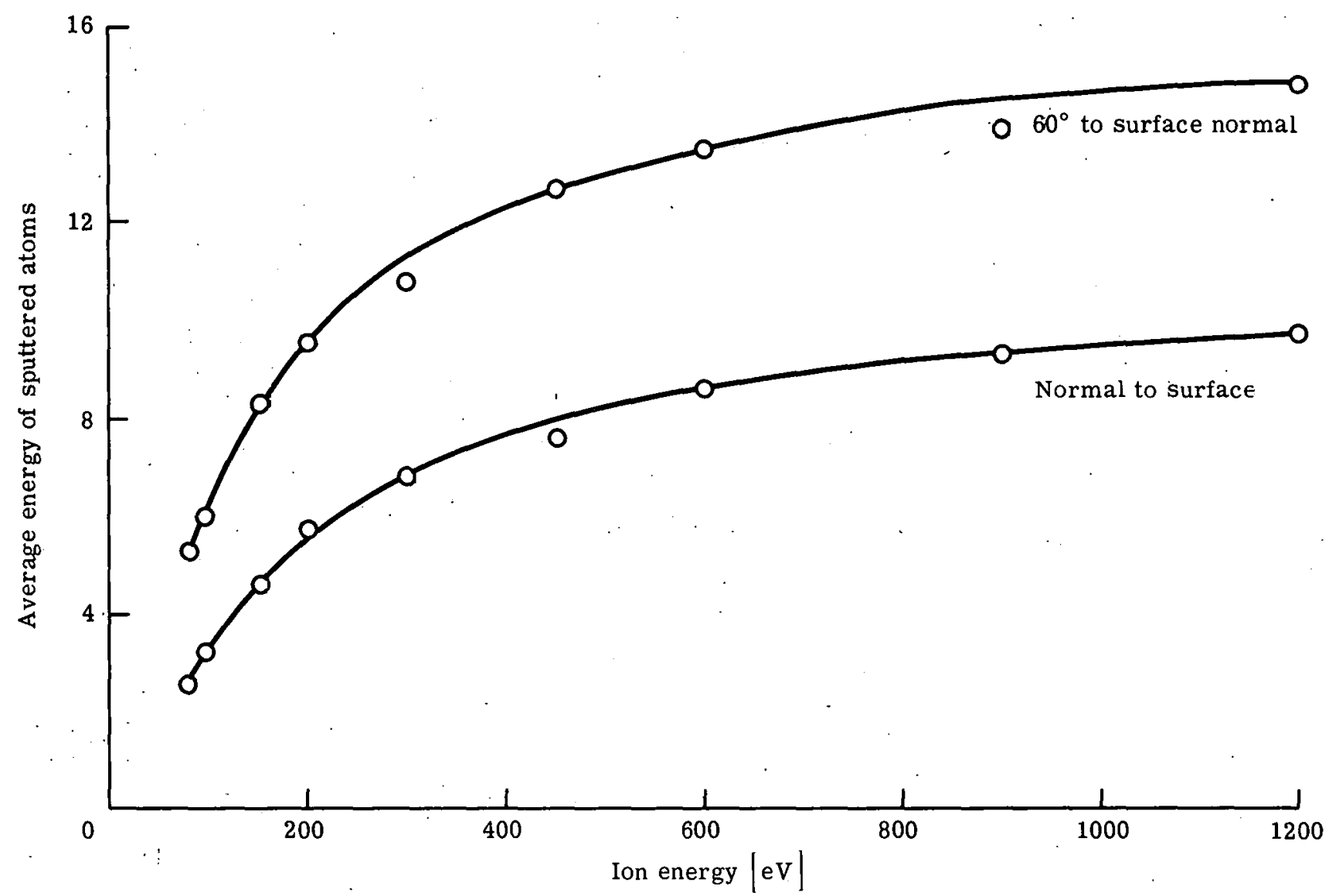

Figure B-7. Average ejection energies of atoms sputtered from a copper (110) surface by $\mathrm{Kr}^{+}$ions. Curves are for ejection normal to the surface and at $60^{\circ}$ to the normal. Stuart and Wehner. 
It has been shown by Campbell and Stirland ${ }^{B 31}$ that sputtering allows the formation of epitaxial films of silver and gold on rock-salt substrates at room temperature rather than the elevated temperatures necessary when using vacuum dcposition. ${ }^{\text {B32 }}$ This effect may be attributed to the greater surface mobility of the depositing sputtered atoms or to the cleaning of the substrate prior to deposition.

Since sputtering removes surface layers, it is often used as a cleaning step in the vacuum deposition process $^{\mathrm{B} 33}$ and in ion plating. This sputter cleaning of the surface is an important aspect of the ion plating process. Mattox and McDonald ${ }^{\mathrm{B} 34, \mathrm{~B} 35}$ have pointed out that the high energies of sputtered atoms may account for the increased adhesion obtained by sputtering noted in many cases.

Since sputtering removes material from different crystallographic planes at different rates, it is used to etch metallographic samples to expose crystal structures. Sputter etching studies have shown that the angle of incidence of the bombarding lons have a definite influence on the resulting etch patterns. ${ }^{\text {B } 6}$ Insulators may be etched by ion bombardment in a manner similar to metals.

There are several variations in the sputtering process which are particularly useful in certain situations. In the usual sputtering setup called diode sputtering there is a single DC high voltage circuit to establish the gas discharge and sputter the material. The material to be sputtered is made the cathode of the circuit and the substrate on which the material is to be deposited is placed on the anode or elsewhere in the system. A variation to this is to use one high voltage circuit to establish the primary gas discharge and a separate bias voltage to extract ions from the plasma and sputter a second cathode. This triode sputtering often uses a hot cathode discharge (see Appendix A) to establish the primary discharge and has the advantage that the current and voltage in the sputtering circuit is independent of the gas pressure.

Maissel and Schaible ${ }^{\text {B37 }}$ have shown that by biasing the substrate negatively during sputtering so that the substrate is being ion bombarded during deposition, films are produced having resistivities lower than those obtained by usual sputtering techniques. This technique is called bias sputtering and the change in film characteristics is attributed to the ion bombardment of the substrate during deposition disassociating the compounds of the film material which are formed, thus producing a more pure film.

The extraction of ions from a low pressure gas discharge gives an ion flux to the sputtering cathode which has a large component of high energy ions (see Appendix A). Since the sputtering yield is proportional, to the ion energy, the sputtering efficiency will be greater using the triode of arrangement than when using diode sputtering. In addition, back diffusion of the sputtered atoms to the sputtering cathode. is minimized since the collision probability near the cathode surface is decreased.

The radio-frequency sputtering of insulators by polarizing the surface has been discussed in Appendix A.

Asymmetrical AC sputtering described by Frerichs ${ }^{B 38}$ uses an $A C$ voltage rather than a DC voltage applied between the material to be sputtered and the substrate. This AC voltage is asymmetrical in such a manner that the material to be sputtered is made more negative during one-half cycle than the substrate is negative during the next half cycle. This allows the sputtering cathode to be bombarded more heavily than the substrate, thus giving a net deposition on the substrate. This bombardment of the substrate by ions during alternate half cycles again produces a more pure film than does ordinary sputtering. ${ }^{\text {B } 39}$ 
Figure B-8 compares the circuitry of the various sputtering setups which have been discussed. $\underline{\text { Reactive sputtering }}^{\mathrm{B} 40}$ uses a reactive gas discharge or a discharge having a mixture of reactive and inert gases. In reactive sputtering, the depositing material reacts with the atmosphere giving a compound film. For instance, tantalum nitride films are often deposited in producing thin film circuitry and are formed by sputtering tantalum in a partial pressure of nitrogen.

Using sputtering, alloys and compounds can be deposited with the same composition as the target material. B42, B43, B44 If the same materials were evaporated, the various constituents would come off at different rates, because of their different vapor pressures, giving a deposit whose composition would - vary with thickness. 

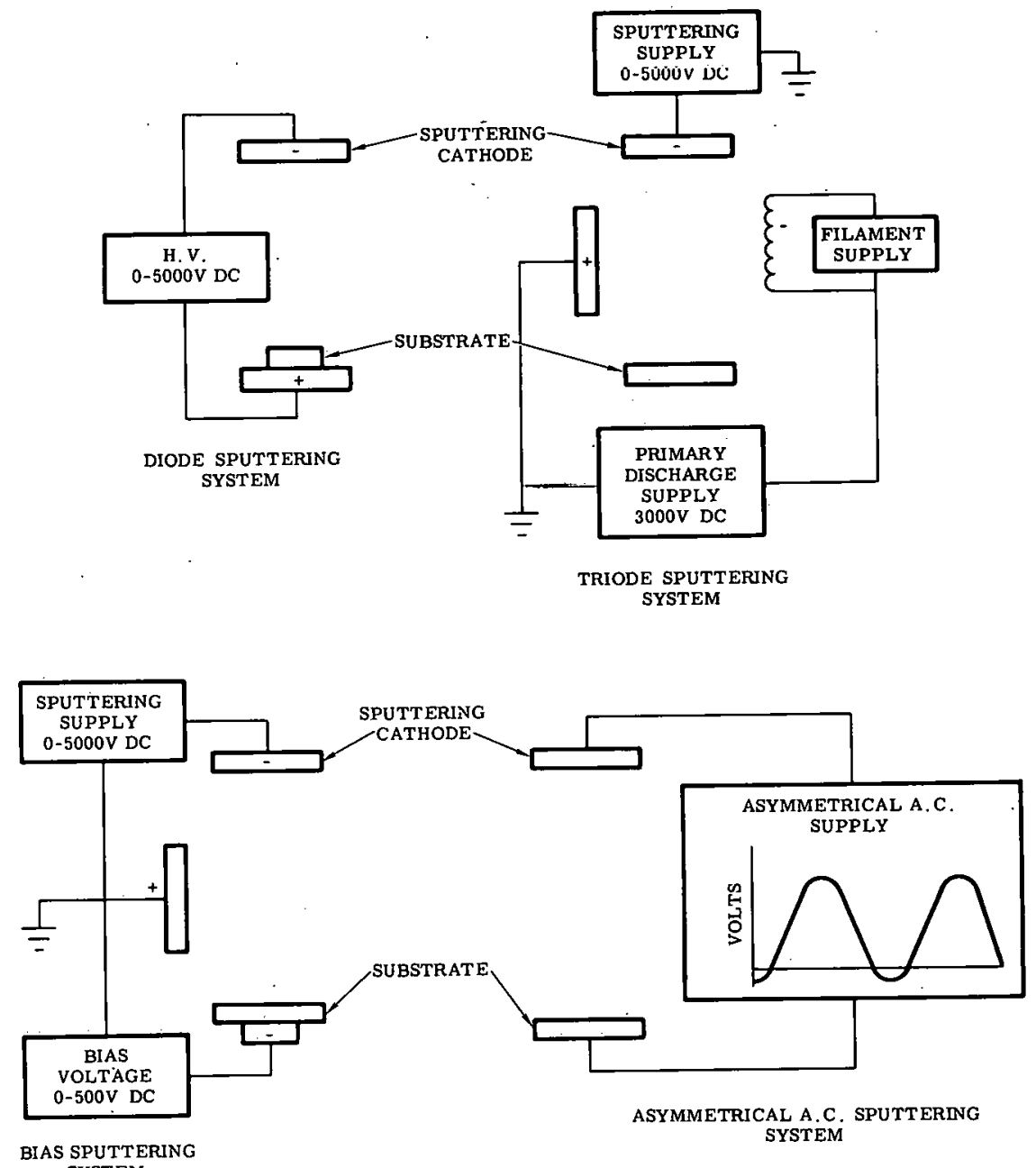

SYSTEM



RF SPUTTERING SYSTEM

Figure B-8. Sputtering Systems 


\section{LIST OF REFERENCES}

B1. Grove, W. R., Phil. Trans. 142B, 87 (1852)

B2. Wright, A. W. , Amer. J. Sci. and Arts 1349 (1877)

B3. Gunther-Schulze, A., Z. Phys. 36563 (1926)

B4. Crookes, W. , Proc. Roy. Soc. (London) 5088 (1891)

-B5. Stark, J., Z. Elektrochem. 14 752(1908), 15509 (1909)

B6. Wehner, G. K., J. Appl. Phys. 301762 (1959)

B7. Seeliger, R., and Sommermeyer, K., Z. Physik 93692 (1935)

B8. Wehner, G. K. , and Rosenberg, D., J. Appl. Phys. 31177 (1960)

B9. Nielsen, K. O., Electromagnetically Enriched Isotopes and Mass Spectroscopy, Butterworths (London) 1956.

B10. Davies, J. A., and Simms, G. A., Can. J. Phys. 39601 (1961)

B11. Nelson, R. S., Phil. Mag. 9343 (1964)

B12. Almén, O. , and Bruce, G. , Nuc. Inst. and Methods 11, 257 (1961)

B13. Almen, O., and Bruce, G., Nuc. Inst. and Methods 11, 279 (1961)

B14. Laegried, N., and Wehner, G. K., J. Appl。 Phys. 32, 365 (1961)

B15. Stuart, R. V., and Wehner, G. K., J. Appl. Phys. 332345 (1962)

R16. Jorgenson, G. V., and Wehner, G. K. , J. Appl. Phys. 362672 (1965)

B17. Davidse, P. D. , and Maissel, L. I. , RF Sputtering-Yield Studies for Various Materials" presented at the Twelfth National Vacuum Symposium (AVS) Sept. 29-Oct. 1, 1965, New York, N. Y.

B18. Anderson, G. S., and Wehner, G. K., J. Appl. Phys. 31, 2305 (1960)

B19. Anderșon, G. S., and Wehner, G. K., J. Appl. Phys. 332017 (1962)

B20. Thompson, M. W. , Phil. Mag. 4139 (1959)

B21. Cooper, C. Burleigh, and Comas, James, J. Appl. Phys. 362891 (1965)

B22. Veksler, V. I. "Soviet Physics JETP 11235 (1960)

B23. Stuart, R. V., and Wehner, G. K. , J. Appl. Phys. 35, 1819 (1964)

B24. Henschke, E. B., Phys. Rev. 106737 (1957).

B25. Henschke, E. B., J. Appl. Phys. 28411 (1957)

B26. Silsbee, R. H. , J. Appl. Phys. 28 1246 (1957)

B27. Carlston, C. E., Magnuson, G. D., Coneaux, A., and Mahadevan, P., Phys. Rev. 138 A759 (1965)

B28. Nelson, R. S. , Phil. Mag. 11291 (1965) 


\section{LIST OF REFERENCES (Cont.)}

B29. Jacobson, R. L., and Wehner, G. K., J. Appl. Phys. 362674 (1965)

B30. Ogilvie, G. J., Sanders, J. V., , and Thomșon, A. A., J. Phys. Chem. Solids 24247 (1963)

B31. Campbell, D. S., and Stirland, D. J., Phil. Mag. 9 703 (1964)

B32. Pashley, D. W., Addvanc. Phys. 5173 (1956)

B33. Holland, L., Vacuum Deposition of Thin Films, p. 74, Chapman and Hall Ltd. (London) 1961

B34. Mattox, D. M. , and McDonald, J. E. , J. Appl. Phys. 342493 (1963)

B35. Mattox, D. M. , Interface Formation and the Adhesion of Deposited Thin Films, Sandia Corporation Report SC-R-65-8 $\overline{52}$

B36. Cunningham, R. L., Haymann, P., Lecomte, C., Moore, W. J., and Trillat, J. J., J. Appl. Phys. $31839(1960)$

B37. Maissel, L. I. , and Schaible, P. M. , J. Appl. Phys. 36237 (1965)

B38. Frerichs, R. J. Appl. Phys. 331898 (1962)

B39. Vatny, F., and Harrington, D. J., J. Electrochem. Soc. 112484 (1965)

B40. Overbeck, C. J., J. Opt. Soc. Amer. 23109 (1933)

B41. Gerstenberg, D., Bell Laboratories Record, p. 365, Nov. 1964

B42. Francombe, M. H. , Trans. 10th Nat. Vac. Sym., MacMillan, p. 316 (1963)

B43. Sinclair, R. W., and Peters, F. G., J. Amer. Ceramic Soc. 4620 (1963)

B44. Wolsky, S. P., and Z. Danuk, E. J., Surface Sci. 1110 (1946) 
DISTRIBUTION:

TID-4500 (46th Ed.) UC- 80 (346)

Manager, Naval Reactors, Division of Reactor Development, U. S. Atomic Energy Commission, Washington, D. C.

Attn: D. L. Leighton

Monsanto Research Corporation, Mound Laboratory; P. O. Box 32, Miamisburg, Ohio 45342 Attn: Library and Record Center, For: R. Grove

Los Alamos Scientific Laboratory, P. O. Box 1663, Los Alamos, New Mexico

Attn: Report Librarian

For: CMB Division (1)

GMX Division (1)

W. Division (1)

University of California, Lawrence Radiation Laboratory, P. O. Box 808, Livermore, California 94551

Attn: Technical Information Division

For: Barney Rubin.

The Dow Chemical Company, Rocky Flats Division, P. O. Box 888, Golden, Colorado 80402

Attn: Records Service Department

For: T. Van Voorous

Union Carbide Nuclear Office, Y-12 Plant Records Department, Bldg. 9711-5,

P. O. Box Y, Oak Ridge, Tennessee

Attn: J. Yagi (1)

E. Zurcher (1)

U. S. Atomic Energy Commission, Oak Ridge Operations Office, P. O. Box E, Oak Ridge, Tennessee 37831 Attn: Technical Information Service

A. L. Field, Jr., Supervisor, Fuel Process Development Materials Department, Westinghouse Electric Corporation, Box 10864; Pittsburgh 36, Pennsylvania

M. Wolley, United Kingdom Atomic Energy Authority, Bldg. F62, Atomic Weapons Research Establishment, Aldermaston, Berkshire, England

STL Library, TRW Space Technology Laboratories, One Space Park, Redondo Beach, California, 90278

T. L. Etherington, Manager, Advanced Engineering, General Electric Co., Hendersonville North Carolina, 28739

Robert Magladry, Martin Co., Nuclear Division, Baltimore, Maryland

Robert Culbertson, Litton Industries, Electron Tube Div. 960 Industrial Road, San Carlos, California

H. Winsker, Senior Design' Engineer, Norden Div. United Aircraft, Helen St. , Norwalk, Connecticut

Wayne Stevenson, Allen-Jones, Inc., 17171 Southwestern Ave., Gardena, California (2) Attn: Art Stone

V. A. Lovejoy, S. R. Delmont Pty., Ltd., 16 Anster Street, Adelaide, South Australia

.T. E. MeDondlo, 1110

W. M. O'Neill, 1120 (5)

D. M. Mattox, 1123 (300)

C. F. Schroeder, 1124

R. I. Couzin, 1124

L. M. Berry, 1130

T. S. Church, 1410

E. G. Franzak, 1430

C. L. Carpenter, 1513

A. P. Gruer, 2130

H. E. Lenander, 2500

A. F. Cone, 2510

D. W. Ballard, 2564

E. P. Quigley, 2565

J. G. Marsh, 3414

D. L. Stewart, 4233-4

T. B. Cook, 5800

A. W. Snyder, 5220

P. D. O'Brien, 5223

L. D. Smith, 5600

I. M. Moore, 7510

J. M. Brierly, 8115

G. W. Anderson, 8140

C. R. Barncord, 8150

L. E. Davies, 8160

D. B. Shuster, 9200

W. F. Carstens, 3410

R. S. Gillespie, 3413

B. R. Allen, 3421

M. G. Randle, 3428-1

E. A. Paxton, 8232

R. C. Smelich, 3415-3 (5) 